Grübler: Krystallinisch. Eiweiss der Kürbissamen. 97

\title{
Ueber ein krystallinisches Eiweiss der Kürbissamen;
}

vorn

\section{Dr. Georg Grübler.}

Seit der Beobachtung Maschke's'), dass das vor ihm von $\mathrm{Hartig}^{2}$ ) in Pflanzen aufgefundene krystallinische Eiweiss auch künstlich dargestellt werden könne, hat das Erscheinen verschiedener chemischer Arbeiten über Pflanzeneiweiss Zeugniss von dem wachsenden Interesse an genauerer Kenntniss dieses Körpers abgelegt. Maschke's Verfahren bestand in Ausziehen der Proteïnkörner von Paranüssen mit Wasser bei $40^{\circ}-50^{\circ}$, Filtriren und Abdampfen des erhaltenen Auszuges bei derselben Temperatur bis zur Krystallisation. Die erhaltenen Eiweisskrystalle beschreibt Maschke als meist sechsseitige, dicke Täfelchen, welche das Licht stark reflectirten und aus einer Verbindung von Caseïn mit einer Säure bestehen sollten.

Nach ihm untersuchte $\mathrm{Nägeli}^{3}$ ) eingehend die physikalischen Eigenschaften der Proteïnkrystalle und nannte letztere in Ermangelung verschiedener, für Krystalle charakteristischer Merkmale, Krystalloide, während Hofmei ster $\mathbf{r}^{4}$ ) für die Bezeichnung "Krystall" eintrat.

Das erste, speciell Untersuchungen pflanzlicher Eiweisskörper behandelnde, grössere Werk verdanken wir Ritthausen. ${ }^{5}$ ) Dieser hat jedoch kxystallinisches pflanzliches Eiweiss nicht besonders berücksichtigt.

1876 veröffentlichte Sachsse ${ }^{6}$ ) die Resultate seiner Untersuchungen über Paranusskrystalloide, und nimmt die

1) Dies. Journ. 74, 436. - Botan. Zeitg. 185̃9, S. 409.

2) Botan. Zeitg. 1855, S. 881 .

3) Sitzungsber. d. Münch. Acad. 1862, 2, 120.

4) Handb. d. physiol. Botanik 1, 395 (1867).

5) Die Eiweisskörper der Getreidearten, Hülsenfrüchte und Oelsamen. Bonn 1872.

$\left.{ }^{6}\right)$ Sitzungsber. d. naturforsch. Ges. zu Leipzig. 1876. Journal f. prakt. Chemie [2] Bd. 23. 


\section{Grübler: Ueber ein krystallinisches Eiweiss}

Existenz eines phosphorsäurehaltigen Eiweisskörpers (Caseïns) in der Paranuss an. Sein in demselben Jahre erschienenes Werk ${ }^{1}$ ) enthält eine ausführliche Zusammenstellung der bis dahin auf dem Gebiete der Krystalloiduntersuchungen erzielten Resultate.

Ein Jahr später brachte $\left.\mathrm{Wey}{ }^{2}\right)$ in seiner Abhandlung auf Grundlage der Merkmale, welche Hoppe-Seyler zur Unterscheidung thierischer Eiweisskörper empfiehlt, eine Eintheilung der pflanzlichen, und bezeichnet danach das Eiweiss der Paranusskrystalle als ein Vitellin. Die von Maschke und Sachsse untersuchten Eiweisskörper hält er für Zersetzungsproducte, entstanden durch die Einwirkung des zur Darstellung angewendeten warmen Wassers auf das Vitellin der Proteïnkörner; ebenso verwirft Weyl die von Ritthausen benutzte Gewinnungsmethode von pflanzlichem Eiweiss mittelst sehr verdünnter Kalilauge, da diese nach ihm auf das genuine Eiweiss verändernd einwirkt. Da bei seiner Darstellungsweise die angeführten Fehler vermieden sind, so nimmt er an, dass nur seinen Verbrennungsanalysen ein reines Vitellin (trotz des gefundenen Aschegehaltes von 2,6\%) gedient habe; seine Analysen ergaben im Vergleich zu denen Sachsse's einen höheren C- und einen niederen S-Gehalt (berechnet für aschefreie Substanz). Die Resultate der Untersuchung gaben schliesslich W eyl Veranlassung, die Frage über die Existenz genuinen Caseins verneinend zu beantworten.

In demselben Jahre erschien eine Mittheilung Schmiedeberg's ${ }^{3}$ ) über die Darstellung krystallinischer Verbindungen aus Pflanzeneiweiss durch Behandeln des letzteren mit Magnesia. Derselbe fällte den in der Wärme bereiteten, wässrigen Auszug der Proteïnörner der Paranuss durch Einleiten von Kohlensäure, digerirte den Niederschlag mit wenig Magnesia bei $40^{\circ}$ einige Zeit und dampfte die erhaltene, warm filtrirte

1) Dic Farbstoffe, Kohlehydrate und Proteinsubst. Leipzig 1876.

2) Beiträge zur Kenntniss thier. u. pflanzl. Eiweisskörper. Zeitschr. t. physiol. Chem. 1, 72 .

$\left.{ }^{3}\right)$ Zeitschr. f. physiol. Chem. 1, 205. 
Lösung unter sorgfältigem Einhalten einer constanten Temperatur von $35^{\circ}-40^{\circ}$ ein, bis zum Erscheinen polyëdrischer Krystalle.

Die im folgenden Jahre von Barbieri $\left.{ }^{1}\right)$ veröffentlichte Arbeit über das Eiweiss der Kürbissamen war hauptsächlich gegen die Kritik W eyl's gerichtet und enthielt vergleichende Versuche über die Brauchbarkeit der Darstellungsmethoden pflanzlichen Eiweisses nach Ritthausen und Weyl, nebst analytischen Belegen; seine Versuche führen ihn zu dem Schlusse, dass beide Methoden identische Eiweisskörper liefern.

1879 veröffentlichte Ritthausen ${ }^{2}$ ) die Ergebnisse seiner eingehenden Untersuchungen über das Eiweiss von Ricinussamen; er erhält hierbei neben anderen Resultaten auch eine Bestätigung seiner bereits früher ausgesprochenen Vermuthung, dass gewisse Samen Eiweisskörper verschiedener Natur enthalten. Die von ihm analysirten Eiweisskörper seines Krystalloidmehles (zumeist octaëdrische Proteïnkrystalle enthaltend) zeichnen sich theils durch hohen Gehalt an Kohlenstoff $(53,8 \%)$, theils durch hohen Stickstoffgehalt $(18,43 \%)$ aus, während der geringe Aschengehalt nach ihm für die Reinheit der untersuchten Substanzen spricht.

$\mathrm{Zu}$ derselben Zeit erschien die Dissertation Schim. per's ${ }^{3}$ ), welche sehr ausführliche Untersuchungen der morphologischen, physikalischen und anatomischen Eigenschaften der Proteïnkrystalle einer grossen Anzahl von Pflanzenarten enthält. Nach ihm gehören die Krystalle der Samen hauptsächlich in zwei Systeme, in die tetraëdrische Hemiëdrie des hexagonalen Systems und in die rhomboëdrische Hemiëdrie des hexagonalen Systems; er bezeichnet diese "organisirten" Krrystalle als "Krystalloide".

Eine wesentliche Erleichterung der Darstellung krystallinischen Eiweisses erzielte Drechsel ${ }^{4}$ ) durch Anwendung

1) Dies. Journ. [2] 18, 102.

2) Pflüg. Archiv 19, Heft 1.

$\left.{ }^{3}\right)$ Inauguraldissert. Strassburg 1878.

4) Dies. Journ. [2] 19, 331 . 


\section{Grübler: Ueber ein krystallinisches Eiweiss}

der Alkoholdialyse. Bei diesem Verfahren wird der Eiweisslösung das Wasser durch eine Membran hindurch mittelst Alkohols sehr allmählich entzogen, die Krystallisation erfolgt sehr gleichmässig, und gewisse fremde Substanzen bleiben theils in der Mutterlauge gelöst, theils werden sie vom Alkohol aufgenommen. Drechsel stellte auf die erwähnte Weise die Magnesiaverbindung des Paranusseiweisses dar und bestimmte zuerst den Wasser- und Asche- resp. Magnesiagehalt derselben. Er fand einen Magnesiagehalt von 1,4\%, und Wassergehalt von $13,8 \%$, während die nach $\mathbf{S c h m i e -}$ deberg's Methode dargestellten Krystalle bei gleichem Magnesiagehalte nur 7,7\% Wasser ergaben; andere unter Anwendung von verdünnter Natronlauge erhaltene Krystalle verloren 15,5\% Wasser und hinterliessen als Asche 3,98\% kohlensaures Natron.

Im Verlaufe weiterer Untersuchungen ist es vor Kurzem endlich Herrn Prof. Drechsel gelungen, aus dem Eiweisse der Paranüsse Krystalle zu erhalten, die an Schärfe und gleichmässig guter Ausbildung der Krystallform nichts mehr zu wünschen übrig lassen. Das hierbei angewendete Verfahren bestand darin, eine in der Wärme gesättigte Lösung von Eiweiss in einer Salzlösung zu bereiten, welche dann bei sehr langsamem Erkalten das Eiweiss krystallinisch wieder ausschied. Da diese Methode einer allgemeinen Anwendung fähig schien, so habe ich auf Anregung des Herrn Prof. Drechsel in dieser Richtung eine Reihe von Versuchen angestellt, deren Resultate ich im Folgenden beschreiben will.

Als Material für meine Untersuchungen wäbltc ich Kürbissamen, da dieselben nach den Angaben Barbieri's sich durch einen hohen Gehalt an Proteïnkörnern auszeichnen. Behufs Gewinnung der letzteren folgte ich in der Hauptsache dem Verfahren von Maschke.

Kürbissamen wurden durch Schälen von ihrer äusseren, harten Hülle befreit, zu gröblichem Pulver zermahlen und daraus durch Schlämmen mit Oel und Petroleumäther die Proteïnkörner isolirt. Letztere setzten sich in der ölhaltigen Flüssigkeit bald zu Boden und konnten, nach Abgiessen der 
überstehenden Flüssigkeit, durch wiederholtes Ausziehen mit Petroleumäther vom Oele befreit werden. Die letzten Spuren anhaftender fettartiger Substanz beseitigte ich durch längeres Behandeln mit gewöhnlichem Aether im Drechsel'schen Extractionsapparate; nach beendeter Extraction verjagte ich den Aether durch sofortiges Durchleiten eines trocknen Luftstromes bis zur völligen Trockne der Masse. Die Proteïnsubstanz stellte so ein feines, weisses, lockeres Pulver dar, welches unter dem Mikroskope nur wenig Zellreste oder amorphe Substanz neben einer grossen Menge von Proteïnkörnern erkennen liess; sie bildete das Ausgangsmaterial meiner weiteren Untersuchungen.

Ich suchte zunächst nach dem Verfahren, welches Schmiedeberg bei Darstellung seiner krystallinischen Eiweissverbindungen beschreibt, die gleichen Verbindungen aus der vorliegenden Proteïnsubstanz zu erhalten. $\mathrm{Zu}$ dem Zwecke digerirte ich die letztere mit der 6-8fachen Menge Wassers bei $40^{\circ}$, filtrirte warm und leitete in das klare, schwach bräunliche Filtrat einen Strom Kohlensäure. Es entstand nach anhaltendem Einleiten endlich eine milchige Trübung, die jedoch auch nach längerem Stehen der Flüssigkeit nur wenig Eiweissniederschlag lieferte; derselbe zeigte mikroskopisch die halb krystallinischen Formen, welche Sachsse ${ }^{1}$ ) an seinem, auf gleiche Weise aus Paranusseiweiss erhaltenen Niederschlage beschreibt. Der Niederschlag löste sich ebenfalls leicht in Chlornatrium und verdünntem Alkali, und schied aus der Lösung des ersteren bei Zusatz von Wasser Eiweiss amorph wieder aus.

Die Menge des erhaltenen Niederschlages war jedoch stets so gering, dass damit die Darstellung einer krystallinischen Eiweissverbindung nicht mit Vortheil auszuführen war.

Ich versuchte nun nach Drechsel's $\left.{ }^{2}\right)$ Verfahren aus dem concentrirten, wässrigen Auszuge der Proteïnsubstanz direct Krystalle zu erhalten, und brachte das klare Filtrat des Auszuges in einen Alkoholdialysator. Nach kurzem

1) Die Farbstoffe etc. der Pflanzen, S. 315.

2) Dies, Journ. [2] 19, 331 . 


\section{Grübler: Ueber ein krystallinisches Eiweiss}

Stehen erfolgte Ausscheidung krystallinischen Eiweisses, sowohl am Boden des Dialysators als körnige Masse, als an der Oberfläche der Flüssigkeit in Form einer zarten Krystallkruste; in beiden Fällen waren mikroskopisch polyëdrische Krystalle deutlich wahrzunehmen, welche stellenweise je nach ihrer Lage scharf begrenzte, scheinbar dreieckige Täfelchen darstellten. Die erhaltene Quantität an Eiweisskrystallen genügte aber auch in diesem Falle nicht zur Anstellung weiterer Versuche. Im Ganzen lieferten die wässrigen Auszüge dieser Proteïnsubstanz eine weit geringere Ausbeute an Eiweiss, als sich bei Benutzung der Paranüsse ergab. Letztere müssen daher einen in reinem Wasser weit leichter löslichen Eiweisskörper enthalten, oder einen grösseren Gehalt an löslichen Salzen, welche die Lösung des Eiweisses vermittelten, besitzen. Ich prüfte daher den schwach sauer reagirenden Auszug der Kürbissamenproteïnsubstanz auf seinen Salzgehalt. Nach Entfernung des Fiweisses mit Ammoniak versetzt, gab der Auszug einen Niederschlag von Phosphaten, während das Filtrat hiervon Kalisalze der Chlorwasserstoffsäure, Schwefelsäure und Phosphorsäure enthielt. Weitere Auszüge derselben Proteïnsubstanz enthielten bei geringerem Salzgehalte auch an Eiweiss nur noch minimale Mengen gelöst, obgleich die mikroskopische Besichtigung in der extrahirten Substanz noch einen fast unverändert grossen Reichthum an Proteïnkörnern erkennen liess; das Wasser war sonach ein höchst ungenügendes Lösungsmittel dieses Eiweisses.

Unter Anwendung des Weyl'schen Verfahrens digerirte ich hierauf die Proteïnsubstanz bei gewöhnlicher Temperatur mit 10proc. Chlornatriumlösung. Innerhalb 12 Stunden war bei öfterem Umrühren alles Eiweiss in Lösung gegangen und konnte letztere nun von dem aus Zellfasern und Globoïden bestehenden Bodensatze abfiltrirt werden. In das mit einigen Tropfen Ammoniak neutralisirte Filtrat trug ich Chlornatrium bis zur völligen Sättigung ein, wodurch eine bei längerem Stehen zunehmende, flockige Ausscheidung erfolgte, die auch bereits von $\mathrm{B}$ arbieri bemerkt und nach der Art des Ausscheidens für Myosin gehalten wurde. Die 
Menge dieser ausgeschiedenen Substanz war hier ebenfalls nur gering, doch genügten die damit angestellten Versuche zu dem Beweise, dass hier Ausscheidung eines anderen Eiweisskörpers nicht vorlag. Der flockige Niederschlag, von der Lösung durch Filtration getrennt, blieb bei entsprechendem Zusatze von Wasser völlig unlöslich, ebenso in Alkali, löste sich jedoch leicht nach Zufügen von wenig Essigsäure oder verdünnten Mineralsäuren; unter dem Mikroskope zeigte er sich als aus sehr kleinen, durchsichtigen, krystallinischen Körnchen bestehend. Auf dem Platinbleche erhitzt, verkohlte er ohne Bildung von ammoniakalischen Dämpfen und hinterliess eine grosse Menge weisser, aus Magnesia bestehender Asche. $\mathrm{Da}$ auch die vorgenommene Prüfung auf Eiweiss ein negatives Resultat ergab, so lassen die erwähnten Eigenschaften die flockige Ausscheidung als zusammenhängende Massen von Globoïden erkennen, die infolge ihrer winzigen Grösse vermuthlich die Poren des Papiers beim Abfiltriren der Lösung passirt hatten. Durch nochmalige Filtration gelang es, die Lösung frei von dieser Masse zu erhalten, und wurde das klare Filtrat nunmehr durch Zusatz einèr grösseren Menge Wassers gefällt. Der hierdurch erhaltene flockige Eiweissniederschlag war rein weiss und besass alle Eigenschaften des Weyl'schen Vitellins. $\left.{ }^{1}\right)$ Der Niederschlag wurde nach Abhebern der überstehenden Flüssigkeit durch Auswaschen mit destillirtem Wasser möglichst von Salzen befreit und zuletzt auf dem Eilter gesammelt. Mit diesem Eiweisse wiederholte ich die Darstellung der krystallinischen Magnesiaverbindung und gelang es mir diesmal, im Alkoholdialysator eine grössere Menge krystallinischer Körner zu erhalten. Eine Analyse derselben ergab:

$0,6252 \mathrm{Grm}$. lufttrockner Substanz verloren bei $110^{\circ} 0,0742 \mathrm{Grm}$. Wasser $=11,86 \%$ und hinterliessen nach dem Glühen 0,0052 Grm. Magnesiaasche $=0,94 \%$ für Trockensubstanz.

Die Asche war schwach gelblich gefärbt, vermuthlich

1) In der ausgefällten salzhaltigen Flüssigkeit erhielt ich durch Kupfersalzlösung nochmals einen Niederschlag, welcher viel phosphorsaures Kupfer und gegen $60 \%$ trocknes Eiweiss enthielt. 


\section{Grübler: Ueber ein krystallinisches Eiweiss}

infolge geringen Eisengehaltes. Im Vergleiche hiermit ist der von Drechsel gefundene Magnesiagehalt der analogen Verbindung des Paranusseiweisses ungefähr um die Hälfte höher.

Bei weiterer Darstellung der noch folgenden krystallinischen Eiweissverbindungen befolgte ich das bereits angedeutete neuere Verfahren Drechsel's, da dieses bis jetzt vor allen anderen den Vorzug einer leichten und sicheren Erzielung gut ausgebildeter Krystalle bietet.

Bei Ausführung dieses Verfahrens vertheilt man frisch gefällten Eiweissniederschlag in wenig Wasser und setzt unter Erwärmen auf annähernd $40^{\circ}$ allmählich so viel der als Lösungsmittel dienenden Salzlösung zu, dass alles Eiweiss gelöst und die Flüssigkeit durchscheinend wird. Hierauf wird im Warmtrichter filtrirt und das völlig klare Filtrat einer möglichst langsamen Ablühlung überlassen. Nach Erkalten der Lösung auf ungefähr $6-8^{0}$ hat sich der grösste Theil des Eiweisses am Boden und an den Wänden des Gefässes in meist mikroskopisch kleinen Krystallen ausgeschieden, während der mehr oder minder grosse Rest in der Mutterlauge gelöst bleibt.

Nach dieser Methode gelang es mir, aus dem Eiweisse der Kürbissamen mittelst Chlornatriumlösung Krystalle zu erhalten, die eine deutlich ausgeprägte Krystallform besassen, die Form eines regulären Octaëders. Nicht immer jedoch war es möglich, nach dem angeführten Verfahren gleichmässig gut ausgebildete Krystalle darzustellen, und waren es namentlich noch zwei Uebelstände, welche sich zuweilen störend entgegenstellten. Diese bestanden in der doppelten Schwierigkeit, bei der langsamen Filtration der Eiweisslösung in der Wärme die Temperatur constant zu halten, und beim Lösen des Niederschlages das erforderliche Quantum an Salzlösung genau einzuhalten, resp. nicht zu überschreiten. Die Nichterfüllung dieser Bedingungen hatte im ersteren Falle eine nur kugelig-krystallinische, im zweiten Falle eine zu geringe oder auch gar keine Ausscheidung des Eiweisses zur Folge. Ich suchte daher die erwähnten Uebelstände bei 
weiterer Darstellung zu umgehen und erreichte diesen Zweck endlich durch folgende Abänderung des Verfahrens.

Gut ausgewaschenen Eiweissniederschlag löste ich bei gewöhnlicher Temperatur in 20proc. Chlornatriumlösung, liess einige Zeit ruhig stehen und erhielt dann nach Filtration eine völlig klare Lösung. Diese versetzte ich mit so viel Wasser, dass eine milchige Trübung entstand, welche nach Erwärmen im Wasserbade auf etwa $30^{\circ}$ wieder verschwand. Die klare Flüssigkeit wurde hierauf nochmals mit Wasser von gleicher Temperatur versetzt, bis eine nur geringe Trübung sichtbar wurde, und wiederum bis zum Verschwinden der Trübung höher erwärmt (zumeist genügt hierbei eine Steigerung auf $40^{\circ}-42^{\circ}$ ). Das Ganze wurde dann, wie früher, einer allmählichen Abkühlung überlassen. Die auf diese Weise dargestellten Krystalle sind zwar ebenfalls mikroskopisch klein, übertreffen jedoch meist die vorigen noch an Grösse und gleichmässig guter Ausbildung der Krystallform.

Die erhaltenen Krystalle waren im frischen Zustande weich und biegsam, liessen sich jedoch durch vorsichtiges Reiben mit einem Glasstabe von den Wänden des Gefässes ablösen und durch gelindes Schütteln auf eine Stelle vereinigen, so dass sie nach Abgiessen der Lauge leicht auf dem Filter gesammelt werden konnten. Der Krystallbrei wurde dann auf einen Saugtrichter gebracht, nach $\mathrm{Ab}$ saugen der Lauge die Krystalle durch Aufgiessen von Wasser gewaschen und nach Durchsaugen von Alkohol und Aether im trocknen Luftstrome getrocknet. Aus der restirenden Lauge konnte durch nochmalige Behandlung mit Wasser noch eine geringe Menge von Krystallen erhalten werden, letztere waren jedoch meist kleiner und theilweise von undeutlicher Form. Die restirenden Laugen fand ich reich an Phosphorsäuresalzen und Eisen.

Eigenschaften der Eiweisskrystalle.

Die Krystalle stellen ein weisses Pulver dar, welches mit wenig Wasser angerührt, unter dem Mikroskope deutliche Octaëder erkennen lässt. Sie lösen sich getrocknet ebenfalls in neutralen Salzen und verdünntem Alkali, wenn 


\section{Grübler: Ueber ein krystallinisches Eiweiss}

auch minder leicht als die feuchten Krystalle. In Wasser sind dieselben unlöslich und behalten auch bei längerer Berührung damit unverändert ihre Krystallform, während die frischen Krystalle sich bald trüben und allmählich in den amorphen Zustand übergehen.

Ueber weitere physikalische und krystallographische Eigenschaften der Krystalle hatte Herr Dr. Schimper in Strassburg die Güte, genauere Untersuchungen anzustellen, und schreibt er darüber Folgendes:

$$
\text { „Krystalle aus Kürbissamen. }
$$

Krystallsystem regulär.

Auftretende Formen: O, zum Theil untergeordnet $\infty 0 \infty$. Häufig $Z$ willinge nach dem Spinellgesetze, mit sehr verkürzter Zwillingsaxe.

Dem Krystallsysteme entsprechend sind die Krystalle völlig isotrop.

Imbibitionsfähigkeit und dadurch bedingte Aufquellung findet bei diesen Krystallen ebenfalls statt; behandelt man die Krystalle mit Alkohol und fügt Wasser hinzu, so sieht man unter dem Mikroskope das Aufquellen stattfinden, unter sehr merklicher Abnahme der Lichtbrechung; sie lagern Jod und Farbstoffe in beliebiger Menge ein. Bildung von Rissen bei Behandlung der trocknen Krystalle mit Wasser findet nicht statt, was wohl auf geringere Sprödigkeit zurückgeführt werden muss (übrigens soll bemerkt werden, dass bei den Krystallen aus Paranüssen die Erscheinung meist nur bei Individuen von bedeutenderer Grösse, als die der Kürbiskrystalle auftritt).

Die Krystalle aus Kürbissamen sind gegen Reagentien etwas resistenter als die aus den Paranüssen; ein ähnlicher Unterschied besteht zwischen den natürlichen Krystallen des Paranusstypus und des Ricinustypus; die Löslichkeit in Ammoniak hört bei geringerer Verdünnung als für die der Paranuss bereits auf; eine verdünnte Jod-Jodkaliumlösung bewirkte Auflösung der Paranusskrystalle, nicht die der Kürbiskrystalle. Gegen Kali und Säuren scheinen sie sich gleich zu verhalten, diese Reagentien bewirken, sowie Am- 
moniak, bei hinreichender Verdünnung ein Zersplittern. Die künstlichen Kürbiskrystalle unterscheiden sich von den natürlichen äusserlich nur durch viel vollkommenere Ausbildung; die Krystallformen sind dieselben. Das Verhalten der natürlichen Kürbiskrystalle habe ich wenig eingehend untersucht, da ihre schlechte Ausbildung sie zu wenig geeigneten Untersuchungsobjecten macht. Ich glaube indess, dass in Bezug auf die Quellbarkeit ein ähnlicher Unterschied besteht, wie zwischen künstlichen und natürlichen Paranusskrystallen; die natürlichen Kürbiskrystalle quellen in Säuren und Alkalien viel stärker auf, als die künstlichen."

Es sei mir gestattet, an dieser Stelle Hrn. Dr. Schimper für diese Mittheilungen meinen aufrichtigen Dank zu sagen.

Die in vielen Punkten herrschende Uebereinstimmung der Eigenschaften der natürlichen und der künstlichen Eiweisskrystalle, namentlich aber die gleiche Krystallform beider sprechen dafür, dass das Eiweiss der künstlichen $K_{r y-}$ stalle das unveränderte der natürlichen ist, demnach das zur Gewinnung benutzte Verfahren eine wesentliche Zersetzung des genuinen Eiweisses nicht befürchten lässt.

Dass die Krystalle wirklich aus Eiweiss bestanden, bewiesen ausser dem angeführten Verhalten gegen Salzlösungen und Wasser, die angestellten Eiweissreactionen (nach Millon, Scherer, Einwirkung von Kupferlösung), welche sämmtlich ein positives Resultat ergaben. Beim Erhitzen auf dem Platinbleche bräunte sich anfangs die Substanz unter Entweichen von Ammoniak, blähte sich stark auf und gab unter Entwicklung des charakteristischen Geruches nach verbranntem Horn und brennbarer Gase eine sehr poröse, leichte Kohle, welche nach dem Glühen eine nur minimale Menge Asche von meist graugrüner Farbe hinterliess.

Weitere Untersuchungen der Krystalle erstreckten sich auf deren Wassergehalt und den Coagulationspunkt der Lösung.

Der Wassergehalt der Krystalle war wegen der Hygroskopicität derselben nur annähernd festzustellen; er variirte, je nach der Dauer des zum Trocknen der frischen 


\section{Grübler: Ueber ein krystallinisches Eiweiss}

Krystalle erfolgten Durchleitens trockner Luft, zwischen 9 bis 14 Proc. Ich habe deshalb eine Norm für den Wassergehalt in der Weise zu erhalten gesucht, dass ich die lufttrockne Substanz im Exsiccator über Chlorcalcium bis zum constanten Gewichte trocknete und dann den beim Erwärmen auf $110^{\circ}$ noch weiter eintretenden. Verlust ermittelte und procentisch berechnete.

\begin{tabular}{l|c|c|c|c|c}
\hline \hline $\begin{array}{c}\text { Menge der } \\
\text { angewendeten } \\
\text { Substanz. }\end{array}$ & $\begin{array}{c}\text { Verlust } \\
\text { im } \\
\text { Exsiceator. }\end{array}$ & $\% \mathrm{H}_{2} \mathrm{O}$ & $\begin{array}{c}\text { Verlust bei } \\
110^{\circ} .\end{array}$ & $\%_{0} \mathrm{H}_{2} \mathrm{O}$ & $\begin{array}{c}\text { Gesammt- } \\
\text { verlust } \\
\%\end{array}$ \\
\hline 0,6260 & 0,0290 & 4,63 & 0,0355 & 5,67 & 10,30 \\
1,0047 & 0,0860 & 8,56 & 0,0552 & 5,49 & 14,05 \\
0,3345 & 0,0140 & 4,22 & 0,0175 & 5,22 & 9,44 \\
$\mathbf{1}, 0390$ & 0,0600 & 5,77 & 0,0505 & 4,86 & 10,63
\end{tabular}

Aus diesen Zahlen ergiebt sich als mittlerer Werth $5,31^{\circ}{ }_{0}$ Wassergehalt der im Exsiccator getrockneten Eiweisskrystalle.

Beim Stehen der Trockensubstanz an der Luft stieg der Wassergehalt in kurzer Zeit wieder bis auf $9-10 \%$ und nahm dann, je nach dem Feuchtigkeitsgrade der umgebenden Luft, nur noch sehr allmählich und wenig zu.

\begin{tabular}{c|c|c|c|c}
\hline $\begin{array}{c}\text { Angewendet } \\
\text { lufttrockne } \\
\text { Substanz. }\end{array}$ & $\begin{array}{c}\text { Trocken- } \\
\text { substanz bei } \\
\mathbf{1 1 0 ^ { \circ } .}\end{array}$ & $\begin{array}{c}\text { Wasser- } \\
\text { verlust } \\
\%\end{array}$ & $\begin{array}{c}\text { Gewicht nach } \\
\text { Stehen an der } \\
\text { Luft. }\end{array}$ & $\begin{array}{c}\text { Zunahme } \\
\%\end{array}$ \\
\hline 0,6260 & 0,5615 & 10,30 & 0,6245 & 10,08 \\
0,4250 & 0,3905 & 8,12 & 0,4325 & 9,71 \\
0,9960 & 0,8930 & 10,34 & 0,9935 & 10,11
\end{tabular}

Der durchschnittliche Wassergehalt des lufttrocknen krystallinischen Eiweisses würde demnach etwa $10 \%$ betragen und vermindert sich derselbe an trockner Luft auf ungefähr die Hälfte $(5,31 \%)$.

Bei Bestimmung der Coagulationstemperatur zog ich zugleich den Salzgehalt der Eiweisslösung in Berücksichtigung; bei der Ausführung benutzte ich Capillarröhrchen und verfuhr nach Art der Schmelpunktbestimmung, indem die 
deutlich eintretende Trübung der Eiweisslösung innerhalb der Capillare als Zeichen der Coagulation angenommen wurde.

Eine Lösung des Eiweisses in einer Lösung

von 1 Gew.-Thl. NaCl und 3 Thln. Wass. trübte sich bei $95^{\circ}$,

\begin{tabular}{|c|c|c|c|c|c|c|c|c|}
\hline$\Rightarrow 1$ & $n$ & $"$ & $" 6$ & " & $"$ & $"$ & $n$ & $"$ \\
\hline$n$ & $"$ & $"$ & $" 9$ & $"$ & $"$ & $"$ & $"$ & $"$ \\
\hline 1 & $n$ & $\eta$ & " 12 & 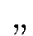 & $\eta$ & 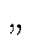 & $\eta$ & 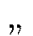 \\
\hline
\end{tabular}

Mit der Zunahme der Concentration der als Lösungsmittel des Eiweisses dienenden Salzlösung erhöht sich sonach entsprechend der Temperaturgrad der Coagulation, eine Beobachtung, welche mit den Resultaten anderer derartiger Bestimmungen in directem Widerspruche steht.

Einwirkung verdünnter Säuren und Alkalien.

Die leichte Veränderlichkeit des frisch dargestellten Eiweisses ist schon seit längerer Zeit Gegenstand von Untersuchungen, doch differiren die Angaben über den Grad der Empfindlichkeit bei Einwirkung von Agentien nicht unbeträchtlich.

Im Anschluss an die vergleichenden Arbeiten Barbieri's über die Brauchbarkeit der Darstellungsmethoden von Eiweiss nach Ritthausen und Weyl habe ich mich bestrebt, den bereits von Barbieri erbrachten Beweisen einen neuen hinzuzufügen, indem ich aus dem nach beiden Methoden erhaltenen Eiweisse die beschriebenen Krystalle darzustellen versuchte. $\mathrm{Zu}$ diesem $\mathrm{Zwecke}$ wurden gleiche Mengen der Proteïnsubstanz je mit verdünnter Kalilauge $(1: 1000)$ und mit 10proc. Chlornatriumlösung extrahirt und die erhaltenen Lösungen gefällt, im ersten Falle durch vorsichtiges Neutralisiren mit Essigsäure, im zweiten durch Zusatz von Wasser. Die erhaltenen Niederschläge wurden gut ausgewaschen und dann unter Erwärmen in Chlornatriumlösung gelöst; nach dem Erkalten Latten beide Lösungen Krystalle ausgeschieden, welche übereinstimmend die octaëdrische Krystallform besassen. Ebenso zeigten die Krystalle beider Darstellungsweisen ein analoges Verhalten in ihrer Löslichkeit in Salzen und verdünntem Alkali, sowie bezüg- 


\section{Grübler: Ueber ein krystallinisches Eiweiss}

lich der Fällbarkeit durch Wasser, resp. Säuren. Diese völlige Gleichartigkeit der erhaltenen Producte zeigt deutlich, dass bei vorsichtiger Anwendung von Ritthausen's Verfahren ein unzersetztes Eiweiss erhalten werden kann. und widerlegt die gegentheilige Behauptung Weyl's.

Beweise für die hohe Empfindlichkeit des frisch gefällten Eiweisses gegen freie Alkalien oder Säuren erhielt ich aber durch folgende Versuche, deren Mittheilung vielleicht nicht ohne Interesse ist.

Bei den verschiedenen Eiweissfällungen nach der Weyl'schen Methode machte ich die Wahrnehmung, dass der erhaltene Niederschlag, je nachdem er mit reinem destillirten, ocier mit kohlensäurehaltigem Wasser ausgefällt worden war. Verschiedenheiten in seinen physikalischen Eigenschaften zeigte. Denn während sich der durch Fällung mit destillirtem Wasser erhaltene, sehr feinflockige, durchscheinende Niederschlag leicht und völlig wasserhell in Chlornatriumsolution löste und deutlich ausgeprägte Krystalle lieferte, war der mit kohlensäurehaltigem Wasser ausgefällte Niederschlag grobflockig, löste sich, wenn er zum Absetzen einige Zeit unter Wasser gestanden hatte, nicht mehr vollständig in Chlornatriumlösung und gab keine octrëdrischen Krystalle, sondern nur undeutlich krystallinische, rundliche Gebilde. Die Ursache dieser Erscheinung konnte sowohl in der zersetzenden Einwirkung der freien Kohlensäure gesucht werden, als auch in der Unreinheit des betreffenden Niederschlages, infolge beigemengter, fremder Substanzen, welche durch Einfluss des kohlensäurehaltigen Wassers mit ausgefällt worden waren. Zur Entscheidung dieser Frage theilte ich einen, durch Fällung mit destillirtem Wasser erhaltenen Eiweissniederschlag in zwei gleiche Theile, rührte den einen mit destillirtem, den anderen mit kohlensäurehaltigem Wasser an und liess Beides in der Kälte über Nacht stehen. Eine am anderen Morgen vorgenommene Prüfung beider Niederschläge auf ihre Eigenschaften ergab genau wieder die bereits erwähnten Verschiedenheiten und constatirte damit die Einwirkung freier Kohlensäure auf das ursprüngliche Eiweiss.

Den Einfluss verdünnter caustischer Alkalien unter- 
suchte ich ebenfalls, und machte sich hier namentlich die Höhe der Temperatur geltend. Dies bewies sowohl die später noch zu erwähnende Fähigkeit äusserst 'verdünnter, wässriger Kalk- und Magnesialösungen $(1: 50,000)$, bei wenig höherer Temperatur relativ grosse Mengen Eiweiss in Lösung zu erhalten, als auch die bei Zimmertemperatur wiederholte Darstellung von Eiweiss nach dem Verfahren Ritthausen's; es war dann das erhaltene Eiweiss nicht mehr ohne starken Rückstand in Chlornatriumlösung löslich und hatte seine Eigenschaft, Krystalle zu bilden, vollständig eingebüsst. Blieb eine Lösung des Eiweisses in Kalilauge der angegebenen Verdünnung ca. zwei Tage bei $10-12^{\circ}$ stehen, so war die beginnende Zersetzung durch Bildung von Ammoniak zu erkennen, welches, wenn auch in geringer Menge, durch Nessler'sches Reagens nachgewiesen werden konnte. Neutrale Alkalisalze halten bekanntlich das Eiweiss auch bei höherer Temperatur lange Zeit unverändert gelöst und verdient in dieser Hinsicht die Weyl'sche Methode der Vitellindarstellung, deren auch ich mich behufs Gewinnung des Eiweisses bediente, den Vorzug.

Nach Darstellung des krystallinischen Eiweisses mittelst Chlornatrium prüfte ich auch das Verhalten anderer Salze in dieser Beziehung und fand, dass die meisten der in Wasser löslichen, neutralen Salze frisch gefälltes Eiweiss in Lösung bringen, jedoch nur die Lösungen der Alkalien und alkalischen Erden das Eiweiss krystallinisch wieder ausschieden.

Ich erhielt Eiweisskrystalle, und zwar durchgängig in Octaëdern, aus Lösungen von:

Essigsaurem, salpetersaurém und phosphorsaurem Natron, Brom- und Jodkalium, Chlorammonium und oxalsaurem Ammon, Chlorbarium und Chlorcalcium, schwefelsaurer Magnesia, gelbem Blutlaugensalz.

Ein besonderes Verhalten zeigten hierbei die Kalksalze insofern, als das Eiweiss in den Lösungen derselben nicht, wie bei anderen Salzen, wasserhell, sondern nur trübe und unter Hinterlassen eines geringen Rückstandes löslich war.

Was die qualitative Untersuchung der Aschen dieser Eiweisskrystalle anlangt, so fand ich im Wesentlichen die 


\section{Grübler: Ueber ein krystallinisches Eiweiss}

bereits bekannten Bestandtheile, wie Eisen, Kalk, Magnesia, Phosphorsäure, immer jedoch noch das beim Lösen des Eiweisses verwendete Salz. Von den mehrfach ausgeführten qualitativen Analysen halte ich, um Wiederholungen zu vermeiden, die Mittheilung einer derselben für genügend; einige Angaben über den Procentgehalt der Eiweisskrystalle (sämmtlich aus Chlornatriumlösung erhalten) an Asche lasse ich vorausgehen.

1,0078 Grm. lufttr. Subst. (=0,8717 Grm. Trockensubst.) gaben $0,0030 \mathrm{Grm}$. Asche $=0,34 \%$ für Trockensubst.

1,0047 Grm. lufttr. Subst. (=0,8635 Grm. Trockensubst.) gaben 0,0023 Grm. Asche $=0,26 \%_{0}$ für Trockensubst.

$1,0240 \mathrm{Grm}$. lufttr. Subst. $(=0,9140 \mathrm{Grm}$. Trockensubst.) gaben $0,0015 \mathrm{Grm}$. Asche $=0,16_{10}^{0}$ für Trockensubst.

Die Asche wurde nach Verkohlen des Eiweisses meist schon nach kurzem Glïhen kohlefrei erhalten, und deshalb die Aschebestimmungen direct auf diese Weise ausgeführt.

Die Farbe dieser Aschen war häufig mehr oder weniger grünlich; der wässrige Auszug der Asche reagirte alkalisch infolge Gehaltes an kohlensaurem Alkali. In concentrirter Salzsäure löste sich die Asche völlig auf und gab nach Verjagen der überschüssigen Salzsäure die Lösung mit essigsanrem Natron einen Eisenniederschlag, in welchem sich durch nolybdänsaures Ammon Phosphorsäure nachweisen liess. In dem Filtrate des Eisenniederschlages entstand nach Zusatz von oxalsaurem Ammon eine schwache Trübung durch Spuren von Kalk, nach Zufügen von Salmiak, phosphorsaurem Natron und Ammoniak ein krystallinischer Niederschlag von phosphorsaurer Ammon-Magnesia. Eine bei letzterer Fällung meist schwach hervortretende Blaufärbung deutete auf Kupfergehalt; es wurden deshalb die Aschen noch speciell auf die Gegenwart von Kupfer geprüft, und letzteres durch Schwefelwasserstoff und gelbes Blutlaugensalz als Aschenbestandtheil positiv nachgewiesen. ${ }^{1}$ )

1) Da (nach Bunsen's Versuchen) das Kupfer möglicherweise erst infolge Anwendung eines Messing-Gasbrenners der Asche beim Glühen zugeführt sein konnte, so veraschte ich andere Mengen Eiweiss unter Anwendung eines gläsemen Brenners, erhielt jedoch dasselbe Resultat. 
Um zu ermitteln, welcher Art die Betheiligung der Salze bei Lösung und Krystallisation des Eiweisses sei, führte ich die nun folgenden Untersuchungen aus:

Zunächst bestimmte ich in den Eiweisskrystallen quantitativ den Gehalt desjenigen Salzes, mit dessen Hülfe das Eiweiss krystallinisch erhalten worden war; dabei ist es vielleicht nicht überflüssig zu bemerken, dass bei einem Gesammtaschengehalte von $0,2-0,3 \%$ die erhaltenen Zahlen Anspruch auf absolute Genauigkeit natürlich nicht machen können. Den Mittheilungen der Ergebnisse dieser Analysen habe ich zugleich die'Resultate der Elementaranalysen (soweit solche ausgeführt wurden) des betreffenden Eiweisses beigefügt.

Eiweisskrystalle aus Chlornatriumlösung.

A. Chlorbestimmung.

Das zu prüfende Eiweiss") wurde in einer geräumigen Platinschale mit Hülfe von wenig reinem kohlensauren Natron in Wasser gelöst, die Lösung zur Trockne verdampft und bei allmählicher Steigerung der Hitze verkohlt. Die Kohle wurde wiederholt mit Wasser extrahirt, die vereinigten Auszüge in einer Platinschale auf ein kleines Volumen verdampft, filtrirt, mit wenig reiner Salpetersäure angesäuert und in dieser Flüssigkeit durch Silberlösung ein weisser Niederschlag erhalten. Letzterer konnte zum Theil auch aus Cyansilber bestehen, da beim Verkohlen des Eiweisses die Bildung von Cyanverbindungen nicht ausgeschlossen war; es wurde deshalb der Silberniederschlag mit wenig verdünnter Salzsäure digerirt, um vorhandenes Cyan an Blausäurebildung zu erkennen. Die letztere war jedoch weder durch Geruch, noch als Berlinerblau nachzuweisen. Der Niederschlag be-

1) Diese Eiweisskrystalle, wie die der folgenden Untersuchungen, waren vorher mit Wasser so lange ausgewaschen worden, bis das ablaufende Waschwasser nicht mehr auf Alkalisalz reagirte. Eine Zersetzung des Eiweisses durch das Behaudeln mit Wasser war nicht z13 bcmerken, da die Eiweisskrystalle nach wie vor ihre Krystallform gut erhalten zeigten.

Journal f. prakt. Chemie [2] Bd. 23. 


\section{Grübler: Ueber ein krystallinisches Eiweiss}

stand demnach nur aus Chlorsilber; cr wurde nach dem Auswaschen auf ein Filter gebracht, getrocknet, mit dem Filter verbrannt und im Porzellantiegel schwach geglüht. Nach dem Glühen wurde er nochmals mit Salpetersäure und Salzsäure behandelt und wieder geglüht.

1,1002 Grm. Subst. $=0,9825 \mathrm{Grm}$. Trockensubstanz gaben 0,0014 Grm. Ag Cl $=0,0004$ Grm. $\mathrm{Cl}=0,04 \%$ für Trockensubst.

\section{B. Natronbestimmung.}

Eiweiss wurde verkohlt, und die Kohle wiederholt mit heissem Wasser extrahirt, filtrirt, auf einem Uhrglase zur Trockne verdampft, gewogen und als kohlensaures Salz berechnet. Nach der Gewichtsbestimmung prüfte ich das Salz auf Natron; nach Behandeln mit Salzsäure erhielt ich Würfel von Chlornatrium; der Flamme ertheilte das Salz eine intensive Gelbfürbung.

1,0240 Grm. Substanz $=0,9140 \mathrm{Grm}$. Trockensubst. gaben 0,0016 Grm. $\mathrm{Na}_{2} \mathrm{CO}_{3}=0,0009 \mathrm{Grm} . \mathrm{Na}_{2} \mathrm{O}=0,1 \% \mathrm{Na}_{2} \mathrm{O}=0,07 \% \mathrm{Na}$.

Danach würde die Trockensubstanz dieser Eiweisskrystalle enthalten haben:

$\begin{array}{ll}\text { Chlor } & 0,04 \% \\ \text { Natrium } & 0,07 \%\end{array}$

Im Vergleiche zum krystallinischen prüfte ich auch das amorphe, nach Weyl's Methode gefällte Eiweiss; dasselbe war ebenfalls entsprechend gut ausgewaschen worden.

Clilorbestimmung: 0,9610 Grm. Subst. $=0,8650 \mathrm{Grm}$. Trockensubst. gaben $0,0012 \mathrm{Grm} . \mathrm{AgCl}=0,00035 \mathrm{Grm} . \mathrm{Cl}=0,04{ }^{\circ}, \mathrm{Cl}$.

Natronbestimmung: 1,7925 Grm. Substanz $=1,5995$ Grm. Trockensubstanz gaben $0,0022, \mathrm{Grm}$. Na.2 $\mathrm{CO}_{3}=0,0013 \mathrm{Grm}$. $\mathrm{Na}_{2} \mathrm{O}=$ $0,09 \% \mathrm{Na}_{2} \mathrm{O}=0,06 \% \mathrm{Na}$.

Elementaranalyse des Eiweisses.

Die Substanz mischte ich in Berücksichtigung ihres Schwefelgehaltes mit chromsaurem Blei, lagerte zwischen Kupferoxyd ein und verbrannte bei vorgelegten Kupferspiralen, zuletzt unter Zuleiten eines Sauerstoffstromes.

Den Stickstoff bestimmte ich volumetriseh nach Dumas, 
unter Benutzung von Magnesit zur Erzengung der Kohlensäure:

Der Wassergehalt der Substanz wurde aus dem Gewichtsverluste bei $110^{\circ}$ berechnet.

Das über die Bestimmung der Bestandtheile hier Gesagte gilt zugleich für die Elementaranalysen der weiterhin noch zu beschreibenden Eiweisskrystalle.

Eiweisskrystalle der Chlornatriumlösung.

Wasser- und Aschebestimmung:

0,9145 Grm. Substanz verloren bei $110^{\circ} 0,0740$ Grm. Wasser $=$ $8,1 \%$, die erhaltenen

0,8405 Grm. Trockensubst. gaben 0,0015 Grm. Asche $=0,18^{0} \%$

Kohlenstoff- und Wasserstoff bestimmung:

0,3390 Grm. Subst. $=0,3116$ Grm. Trockensubst. gaben:

$0,2036 \mathrm{Grm} . \mathrm{H}_{2} \mathrm{O}=0,02262$ Grm. $\mathrm{H}=7,25 \% \mathrm{H}$.

$0,6080 \quad, \quad \mathrm{CO}_{2}=0,1658 \quad, \quad \mathrm{C}=53,21, \mathrm{C}$.

0,3150 Grm. Subst. $=0,2895$ Grm. Trockensubst. gaben:

$0,1887 \mathrm{Grm} . \mathrm{H}_{2} \mathrm{O}=0,020966$ Grm. $\mathrm{H}=7,24 \% \mathrm{H}$.

$0,5650 \quad, \quad \mathrm{CO}_{2}=0,1541 \quad, \quad \mathrm{C}=53,23, \mathrm{C}$.

0,2840 Grm. Subst. $=0,2610 \mathrm{Grm}$. Trockensubst. gaben:

0,1684 Grm. $\mathrm{H}_{2} \mathrm{O}=0,01872$ Grm. $\mathrm{H}=7,17 \% \mathrm{H}$.

$0,5090 \quad, \quad \mathrm{CO}_{2}=0,1388 \quad, \quad \mathrm{C}=53,19, \mathrm{C}$.

Schwefelbestimmung:

1,2888 Grm. Subst. v. $12,5 \%$ Wassergeh. $=1,1124$ Grm. Trockensubstanz gaben 0,0865 Grm. Ba $\mathrm{SO}_{4}=0,01189 \mathrm{Grm} . \mathrm{S}=1,06 \% \mathrm{~S}$.

0,4478 Grm. Subst. $=0,3918$ Grm. Trockensubstanz gaben 0,0298 Grrn. $\mathrm{BaSO}_{4}=0,00409$ Grm. $\mathrm{S}=1,08 \% \mathrm{~S}$.

Stickstoff bestimmung:

$0,2420 \mathrm{Grm}$. Sulst. v. 9,71\% Wassergel. $=0,2185$ Grm. Trockensubstanz gaben $35,6 \mathrm{Ccm}$. $\mathbf{N}$ bei $15,6^{\circ}$ und $769,0 \mathrm{Mm}$. Bar. $=0,04207$ Grm. $\mathbf{N}=19,25 \% \mathrm{~N}$.

0,1875 Grm. Subst. v. $7,80^{\circ}$ Wassergeh. $=0,1728$ Grm. Trockensubstanz gaben $29,0 \mathrm{Ccm}$. $\mathrm{N}$ bei $16^{\circ}$ und $745,0 \mathrm{Mm}$. Bar. $=0,03316$ Grm. $\mathrm{N}=19,19 \% \mathrm{~N}$. 
116 Grübler; Ueber ein krystallinisches Eiweiss

Tabelle der procentischen Werthe.

\begin{tabular}{l|r|r|r|r}
\hline \hline Analyse. & I. & II. & III. & Mittelwerthe. \\
\hline C & 53,21 & 53,23 & 53,19 & 53,21 \\
H & 7,25 & 7,24 & 7,17 & 7,22 \\
N & 19,25 & 19,19 & - & 19,22 \\
S & 1,06 & 1,06 & - & 1,07 \\
O & - & - & - & 19,10 \\
Asche & 0,18 & 0,18 & 0,18 & 0,18 \\
& & & & 100,00
\end{tabular}

Eiweisskrystalle aus Lösung von schwefelsaurer Magnesia.

Die Darstellung dieser Krystalle war derjenigen mittelst Chlornatriumlösung gleich, doch erschienen mir die hier erhaltenen Eiweisskrystalle grösser als die vorigen, und, nach dem Aschengehalte zu schliessen, leichter rein zu erhalten; Krystallform ebenfalls octaëdrisch; der Aschengehalt betrug etwas über 0,1 Procent:

a) 1,0070 Grm. Subst. verloren bei $110^{\circ} 0,0917$ Grm. Wasser $=$ $9,10_{10}$; die erhaltenen $0,9153 \mathrm{Grm}$. Trockensubstanz gaben 0,0013 Grm. Asche $=0,14 \%$.

b) 1,2050 Grm. Subst. verloren bei $110^{\circ} 0,1145$ Grm. Wasser $=$ $9,5 \%$; die erhaltenen $1,0905 \mathrm{Grm}$. Trockensubstanz gaben $0.0015 \mathrm{Grm}$. Asche $=0,13^{\circ}{ }_{0}$.

Die Aschen waren rein weiss und wollig voluminös; sie lösten sich vollständig in Salzsäure und liessen in dieser Lösung Spuren von Eisen und Phosphorsäure nachweisen.

Die Asche der Substanz b) prüfte ich quantitativ auf den Magnesiagehalt. Behufs dessen stellte ich die salzsaure Lösung dieser Asche dar, fällte in dieser durch essigsaures Natron die vorhandene Spur phosphorsäurehaltigen Eisens und versetzte das Filtrat hiervon zur Ausscheidung der Magnesia nach. Zufügen von Salmiak und phosphorsaurem Natron mit Ammoniak. Der erhaltene Niederschlag der phosphorsauren Ammon-Magnesia ergab nach dem Glühen: $0,0034 \mathrm{Grm} .2 \mathrm{MgO} \mathrm{PO}_{5}=0,0012 \mathrm{Grm} . \mathrm{MgO}=0,11 \mathrm{Grm}$. für Trockensubstanz. 
Bestimmung von Schwefelsäure und Magnesia dieser Eiweisskrystalle.

A. Bestimmung der Schwefelsäure.

1,8707 Grm. Subst. (=1,7024 Grm. Trockensubst.) wurden durch Digestion mit salzsäurehaltigem Wasser in eine klare Lösung von Syntonin verwandelt, und letztere heiss mit wenig Chlorbariumlösung versetzt. Die hierdurch entstandene Trübung zeigte die Bildung von schwefelsaurem Baryt an, der sich nach mehrtägigem Stehen allmählich zu Boden setzte. Die überstehende klare Flüssigkeit wurde hierauf durch ein kleines Filter gegossen, zuletzt der Barytniederschlag auf das Filter gespült, mit heissem Wasser ausgewaschen, getrocknet und geglüht. Ich erhielt

0,0102 Grm. $\mathrm{Ba} \mathrm{SO} \mathrm{O}_{4}=0,0035$ Grm. $\mathrm{SO}_{3}=0,20 \% \quad \mathrm{SO}_{3}$ für Trockensubstanz.

\section{B. Magnesiabestimmung.}

Die als Filtrat vom schwefelsauren Baryt erhaltene Syntoninlösung wurde sammt Waschwasser zur Trockne verdampft, der Rückstand verkohlt, die Kohle mit heissem, salzsäurehaltigen Wasser mehrmals extrahirt und die vereinigten Auszüge auf ein kleines Volumen verdampft. Der in letzterem noch enthaltene Baryt wurde durch Schwefelsäurezusatz entfernt und das Filtrat hiervon bis fast zur Trockne eingedampft. Die concentrirte wässrige Lössung des Rückstandes gab, erst mit Weinsäure, dann mit Salmiak, phosphorsaurem Natron und Ammoniak versetzt, einen krystallinischen Niederschlag von phosphorsaurer Ammon-Magnesia. Aus diesem erhielt ich nach dem Gilühen:

0,0064 Grm, $2 \mathrm{MgOPO}_{5}=0,0023$ Grm. $\mathrm{MgO}=0,13 \% \mathrm{MgO}$ für Troekenanbstanz.

Eine Zusammenstellung der erhaltenen procentischen Werthe für $\mathrm{MgO}$ und $\mathrm{SO}_{3}$ ergiebt annähernd die Zusammensetzung der schwefelsauren Magnesia:

Gefunden: $\mathrm{MgO}: 13$ Thle.

$\mathrm{SO}_{3}: \frac{20 "}{33 \text { Thle. }}$

Berechnet: MgO: 10 Thle.

$$
\mathrm{SO}_{3}: 20 "
$$


118 Grübler; Ueber ein krystallinisches Eiweiss

Elementaranalysen.

Wasser- und Aschebestimmung.

1,2050 Grm. Substanz verloren bei $110^{\circ} 0,1145$ Grm. Wasser $=$ 9,50 $\%$; die erhaltenen $1,0905 \mathrm{Grm}$. Trockensubst. gaben 0,0015 Grm. Asche $=0,13 \%$.

Kohlenstoff- und Wasserstoff bestimmung.

$0,5530 \mathrm{Gr} \cdot \mathrm{m}$. Subst. $=0,5005 \mathrm{Grm}$. Trockensubst. gaben :

0,3162 Grm. $\mathrm{H}_{2} \mathrm{O}=0,03514$ Grm. $\mathrm{H}=7,02{ }^{\circ}{ }_{0}$.

$0,9785 \quad " \mathrm{CO},=0,2669 \quad, \mathrm{C}=53,32$ "

0,4445 Grm. Subst. $=0,4022$ Grm. Trockensubst. gaben:

$0,2523 \mathrm{Grm} . \mathrm{H}_{2} \mathrm{O}=0,02804 \mathrm{Grm} . \mathrm{H}=6,97{ }^{\circ}{ }_{0}$.

$0,7880 \quad, \quad \mathrm{CO}_{2}=0,2104 \quad, \mathrm{C}=53,27$,

Stickstoff bestimmung:

0,2905 Grm. Subst. $=0,2628 \mathrm{Grm}$. Trockensubst. gaben 43,0 Ccm. $\mathrm{N}$ bei $14,2^{\circ}$ und $747.5 \mathrm{Mm}$. Bar. $=0,0497 \mathrm{Grm} . \mathrm{N}=18,89 \%$.

$0,2550 \mathrm{Grm}$. Subst. $=0,2306 \mathrm{Grm}$. Troekensubst. gaben 38,5 Ccm.

$\mathrm{N}$ bei $17,8^{0}$ und $746,0 \mathrm{Mm}$. Bar. $=0,0436 \mathrm{Grm} . \mathrm{N}=18,90 \%$.

0,2245 Grm. Substanz (von 10,11\% ${ }_{0}$ Wassergeh.) $=0,2019 \mathrm{Grm}$. Trockensubstanz gaben $32,5 \mathrm{Ccm}$. $\mathrm{N}$ bei $10,7^{\circ}$ und $757,5 \mathrm{Mm}$. Bar. $=$ 0,03856 Grm. $\mathrm{N}=19,10^{\circ} \mathrm{o}$.

Schwefelbestimmung:

$0,6860 \mathrm{Grm}$. Substanz $=0,5750 \mathrm{Grm}$. Trockensubst. gaben 0,0411 Grm. $\mathrm{BaSO}_{4}=0,06616$ Grm. $\mathrm{S}=1,14 \% \mathrm{~S}$.

0,6695 Grm. Substanz $=0,6019$ Grm. Trockensubst. gaben 0,0490 Grm. $\mathrm{BaSO}_{4}=0,0673$ Grm. $\mathrm{S}=1,12 \% \mathrm{~S}$.

Procentische Werthe für Trockensubstanz.

\begin{tabular}{l|r|r|r|r}
\hline & Analyse I. & Analyse II. & Analyse III. & Mittelwerthe. \\
\hline C & 53,32 & 53,27 & - & 53,29 \\
H & 7,02 & 6,97 & - & 6,99 \\
N & 18,89 & 18,90 & 19,10 & 18,99 \\
S & 1,14 & 1,12 & - & 1,13 \\
O & - & - & - & 19,47 \\
Asche & 0,13 & 0,13 & - & 0,13 \\
& & & & 100,00
\end{tabular}

Eiweisskrystalle der Chlorammoniumlösung.

Für die Gewimung dieses krystallinischen Eiweisses gilt im Allgemeinen das bisher darüber Gesagte, ebenso über 
Krystallform und Eigenschaften. Dass der Aschegehalt etwas geringer gefunden wurde, rührt wohl daher, dass das an der Eiweisskrystallisation betheiligte Salz ein in der Hitze flüchtiges war.

$0,9333 \mathrm{Grm}$. Substanz $=0,8265 \mathrm{Grm}$. Trockensubst. gaben 0,0008 Grm. Asche $=0,09 \%$.

Die Asche besass eine schwarzbraune Farbe und bestand zum grössten Theile aus Kupferoxyd, neben Spuren von Eisen und Phosphorsäure.

Beim Veraschen der Substanz im bedeckten Platintiegel bildete sich kurz vor Beginn der Verbrennung an Deckel und Wänden des Platintiegels ein schwacher, weisser Beschlag, der sich in Wasser leicht löste und nach Verdampfen der Lösung zur Trockne sich bei stärkerem Erhitzeń wieder verflüchtigte; der Beschlag bestand demnach vermuthlich aus dem Chlorammonium des Eiweisses.

Einen weiteren Beweis für den Chlorammoniumgehalt dieses Eiweisses erhielt ich durch folgenden Versuch:

Eine bestimmte Gewichtsmenge des trocknen krystallinischen Eiweisses wurde in einer kleinen Schale in wenig Chlornatriumlösung gelöst, dann mit 0,1proc. Kalilauge versetzt, und die Schale bedeckt mit einer gut schliessenden Glasplatte, an deren innerer Seite sich ein Tropfen concentrirter Schwefelsäure befand. Mit einer gleich grossen Menge salmiakfreien Eiweisses wurde ebenso verfahren, um hierdurch ein Vergleichsobject der Einwirkung der Kalilauge auf reines Eiweiss zu haben. Beide Schälchen wurden in einem kalten, ammoniakfreien Raume aufbewahrt. Nach Verlauf eines Tages wurde die Schwefelsäure beider Glasplatten, mittelst wenig Wassers in Reagensgläser gespült und nach Zusatz überschüssiger Kalilange durch Nessler'sches Reagens auf Ammoniak geprüft. In der ersteren Flüssigkeit entstand bald Gelbfärbung, während in der anderen Lösung erst nach längerer Zeit diese Erscheinung auftrat.

Bei Wiederholung dieses Versuches unter Anwendung stärkerer Kalilauge liess sich dasselbe beobachten, nur unter entsprechend stärkerem Hervortreten der Ammoniakreaction. 


\section{Grübler: Ueber ein krystallinisches Eiweiss}

Die erlangten Resultate sprechen sowohl für die Gegenwart des Chlorammoniums in den betreffenden Eiweisskrystallen, als auch für den bereits früher erwähnten, zersetzenden Einfluss verdünnter Kalilauge bei längerer Einwirkung auf Eiweiss.

Was den erwähnten reichlichen Kupfergehalt der Eiweisskrystalle betriffit, so war es möglich, dass das Kupfer erst während der Darstellung als Verunreinigung in das Eiweiss gelangt war, und untersuchte ich deshalb eine grössere Menge der ursprünglich verwendeten Proteïnsubstanz. Sie gab, unter Anwendung eines gläsernen Brenners verbrannt, eine Asche, in welcher durch Schwefelwasserstofi, Ammoniak und dureh gelbes Blutlaugensalz wiederum Kupfer deutlich nachgewiesen werden konnte.

Da auch nach dem später beschriebenen, mehrmaligem Umkrystallisiren dieses Eiweisses eine Verminderung des Kupfergehaltes nicht zu bemerken war, so muss nach diesen Beobachtungen das Kupfer als mit dem Eiweiss verbunden angesehen werden.

Das Quantum der aus Chlorammoniumlösung erhaltenen Eiweisskrystalle war bei guter Ausbildung der letzteren stets ein sehr reichliches, und benutzte ich diesen Umstand zu dem Versuche, dieses krystallinische Eiweiss mehrmals umzukrystallisiren. Ich hoffte hierbei auf Grund der bereits angedeuteten Wahrnehmung, dass die Mutterlauge der Eiweisskrystalle stets stärker phosphorsäurehaltig war, als eine Lösung der daraus erhaltenen Krystalle, das Eiweiss schliesslich phosphorsäurefrei zu erhalten. Behufs dessen wurden aus einer grösseren Menge frisch gefällten Eiweisses mittelst Chlorammoniumlösung Krystalle dargestellt, letztere durch Abgiessen und Absaugen auf einem Filter von der Lauge möglichst befreit, noch feucht von Neuem gelöst und wiederum zum Krystallisiren gebracht. Auf diese Weise wurden die zuerst erhaltenen Frystalle noch dreimal umkrystallisirt. Nach jeder Krystallisation wurde ein bestimmtes Quantum des Eiweisses mittelst molybdänsauren Ammons geprüft und, wemn noch Phosphorsäure nachweisbar, von Neuem umkrystallisirt. Die Abnahme an Phosphorsäure war nach jeder Krystallisation deutlich wahrzunehmen, so dass endlich in 
dem bei der vierten Krystallisation erhaltenen Eiweisse keine, in der davon restirenden Lauge eine nur schwer erkennbare Spur von Phosphorsäure mehr nachzuweisen war. Dass ich nach Trocknen der Krystalle bei Prüfung einer grösseren Menge (ca. 1,0 Grm. lufttrockner Substanz) in etwa 0,0010 Grm. kupferhaltiger Asche trotzdem noch eine Spur Phosphorsäure fand, könnte nur zur Annahme einer Verbindung der phosphorsauren Salze mit dem Eiweisse führen.

\section{Elementaranalysen.}

Die hierzu verwendete Substanz bestand in dem durch Umkrystallisiren gereinigten Eiweisse der Chlorammoniumlösung.

Wasser- und Aschebestimmung:

$0,8255 \mathrm{Grm}$. Subst. verloren bei $110^{\circ} 0,0785 \mathrm{Grm}$. Wasser $=9,5^{\circ} ; 0 ;$ die erhaltenen 0,7470 Grm. Trockensubst. gaben 0,0008 Grm. Asehe $=0,11 \%$.

Kohlenstoff- und Wasserstoff bostimmung:

0,3595 Grm. Substanz $=0,3254$ Grm. Trockensubst. gaben:

0,2139 Grm. $\mathrm{H}_{2} \mathrm{O}=0,02376$ Grm. $\mathrm{H}=7,31 \%$,

$0,6380 \quad, \quad \mathrm{CO}_{2}=0,1740 \quad, \mathrm{C}=53,47$,

0,2855 Grm. Substanz $=0,2544$ Grm. Trockensubst. gaben :

0,1704 Grm. $\mathrm{H}_{2} \mathrm{O}=0,01893$ Grm. $\mathrm{H}=\mathbf{7 , 3 2} \%$,

$0,5085 \quad, \quad \mathrm{CO}_{2}=0,1368 \quad$ C $=53,63$,

Stickstoffbestimmung:

0,1700 Grm. Subst. $=0,1541$ Grm. Trockensubst. gaben 25,5 Ccm. $\mathrm{N}$ bei $14,4^{0}$ und $756,0 \mathrm{Mm}$. Bar. $=0,02978 \mathrm{Grm} . \mathbf{N}=19,33 \% \mathrm{~N}$.

0,1810 Grm. Subst. $=0,1638 \mathrm{Grm}$. Trockensubst. gaben $27,0 \mathrm{Cem}$. $\mathrm{N}$ bei $13,0^{\circ}$ und $750,8 \mathrm{Mm}$. Bar. $=0,03150 \mathrm{Grm} . \mathrm{N}=19,23 \% \mathrm{~N}$.

0,3308 Grm. Subst. $=0,2994$ Grm. Trockensubst. gaben 48,0 Ccm. $\mathbf{N}$ bei $15,6^{\circ}$ und $767,0 \mathrm{Mm}$. Bar. $=0,05698 \mathrm{Grm} . \mathbf{N}=19,03 \% \mathbf{N}$.

Schwefelbestimmung:

$0,3345 \mathrm{Grm}$. Substanz $=0,3030$ Grm. Trockensubst. gaben 0,0256 Grm. $\mathrm{BaSO}_{4}=0,003516$ Grm. $\mathrm{S}=1,16 \% \mathrm{~S}$. 
122 Grübler: Ueber ein krystallinisches Eiweiss

Procentische Werthe für Trockensubstanz.

\begin{tabular}{l|c|c|c|c}
\hline & Analyse I. & Analyse II. & Analyse III. & Mittelwerthe. \\
\hline C & 53,47 & 53,63 & - & 53,55 \\
H & 7,31 & 7,32 & - & 7,31 \\
N & 19,23 & 19,03 & 19,33 & 19,17 \\
S & 1,16 & - & - & 1,16 \\
O & - & - & - & 18,70 \\
Asche & 0,11 & 0,11 & - & 0,11 \\
& & & & 100,00
\end{tabular}

In Verbindung mit dem beschriebenen Versuche über Entfernung der Phosphorsäure aus Eiweiss scheint mir noch das nachstehend Mitgetheilte über die Beziehung der Phosphorsäure zum Eiweiss nicht ohne einiges Interesse zu sein.

Ein Vergleich der bis jetzt vorhandenen Angaben über den Phosphorsäuregehalt des pflanzlichen Eiweisses lässt zunächst erkennen, dass mit der zunehmend besseren Reindarstellung der untersuchten Substanzen eine entsprechende Abnahme des Gehaltes an Phosphorsäure (und Asche) verbunden ist. So findet z. B. Ritthausen ${ }^{1}$ ) bei seinen Untersuchungen von Ricinussameneiweiss bei $2-3 \%$ Aschegehalt einen Phosphorsäuregehalt von $1,85 \%$, welcher sich bei dem gereinigten Producte auf $1,51 \%$ verminderte. Sachsse ${ }^{2}$ ) findet im Paranusseiweiss (nach Maschke's Verfahren gewonnen) bei minimalem Aschengehalte, resp. in aschefreier Substanz, nur 0,82\% Phosphorsäure; er nimmt deshalb an, dass dieselbe ein wirklicher Bestandtheil seines aschefreien Eiweisses ist. ${ }^{3}$ )

Eine beträchtliche Verminderung des Phosphorsäuregehaltes ergab sich ferner bei Untersuchung des krystallinischen Kürbissameneiweisses im Vergleiche zum amorphen, welches durch Fällen mit Kupferlösung erhalten worden war.

1) Die Eiweisskörper etc. S. 185.

2) Die Farbstoffe etc. $\$$. 316.

3) Weyl dagegen schliesst aus seinen, ebenfalls mit Paranusseiweiss angestellten Untersuchungen, dass Phosphorsäure und Asche hier nur als Verumreinigung zu betrachten sind, und berechnet dementsprechend die Elementaranalysen seines Vitellins. 
1) Amorphes Eiweiss.

0,7895 Grm. Substanz $=0,7099 \mathrm{Grm}$. Trockensubst. gaben 0,0168 Grm. $2 \mathrm{MgOPO}=0,0107$ Grm. $\mathrm{P}_{2} \mathrm{O}_{5}=1,55^{0} 0_{0}$.

2) Krystallinisches Eiweiss.

0,7055 Grm. Substanz = 0,6882 Grrn. Trockensubst. gaben 0,0028 Grm. $2 \mathrm{MgOPO}_{5}=0,0018$ Grm. $\mathrm{P}_{2} \mathrm{C}_{5}=0,26 \%$.

$0,7220 \mathrm{Grm}$. Substznz $=0,6550 \mathrm{Grm}$. Trockensubst. gaben 0,0024 Grm. $2 \mathrm{MgOPO}=0,0015$ Grm: $\mathrm{P}_{2} \mathrm{O}_{5}=0,23{ }^{\circ}{ }_{10}$.

Zur Bestimmung der Phosphorsäure löste ich das Eiweiss in verdünnter Kalilauge, verdampfte in einer Porzellanschale zur Trockne und verkohlte. Die Kohle wurde mit salzsäurehaltigem Wasser ausgezogen, die Auszüge zur Trockne verdampft, wieder in wenig Wasser gelöst und in dieser Lösung nach Zusatz von wenig Weinsäure die Magnesia als phosphorsaure Ammon-Magnesia gefällt.

Die mit der weiter getriebenen Reinigung des Eiweisses verbundene Abnahme an Phosphorsäure und Asche macht zwar die vorherrschende Annahme, dass die gefundene Phosphorsäure nur als schwer vom Eiweisse zu trennende Verunreinigung anzusehen sei, wahrscheinlicher, schliesst jedoch, wie bereits angedeutet, die Möglichkeit einer Verbindung phosphorsaurer Salze mit Eiweiss nicht aus.

Eiweisskrystalle aus Chlorcalciumlösung.

Ein von dem der bisher angeführten Salze etwas verschiedenes Verhalten zeigen die Kalksalze gegen Eiweiss, da mit Chlorcalcium eine klare Lösung nicht erzielt werden konnte. Die Lösung klärt sich weder durch Zusatz von mehr Chlorcalciumlösung, noch bei Steigerung der Temperatur, im letzteren Falle tritt sogar bei ungefähr $40^{\prime \prime}$ Ausscheidung des Eiweisses in grossen, käsigen, unlöslichen Flocken ein. Dieselben bilden nach dem Absetzen eine schwammige, zähe, gewebeähnliche Masse, welche nach dem Trocknen hart und hornartig durchscheinend wurde.

Um diese Uebelstände zu vermeiden, versetzte ich den Eiweissniederschlag behufs Lösung so lange unter Umschütteln abwechselnd mit Wasser und Chlorcalciumlösung, bis 


\section{Grübler: Ueber ein krystallinisches Eiweiss}

kein ungelöstes Eiweiss mehr sichtbar war. Die auch hier schwach trübe erhaltene Lösung schied nach kurzem Stehen wenige Flocken aus und gab dann ein völlig wasserhelles Filtrat. Letzteres wurde zur Darstellung krystallinischen Eiweisses unter Wasserzusatz wie früher behandelt, beim Erwärmen jedoch eine Temperatur von $30^{n}$ nicht erheblich überschritten.

Das ausgeschiedene Eiweiss war ebenfalls octaëdrisch krystallisirt, doch besassen die Krystalle meist eine undeutliche Form. Beim Stehen an der Luft trockneten sie bald zu einer glasigen Masse, welche, mit Wasser übergossen, allmählich milchweiss wurde, schwach aufquoll und sich dann in Form einer zähen Haut vom Glase abziehen liess. Diese Haut war in Chlornatriumlösung, und verdünntem Alkali unlöslich, während dies bei frisch erhaltenen Krystallen desselben Eiweisses, ebenso bei gut getrockneten, nicht der Fall war. Den Kalkgehalt der Krystalle vermochte ich in der Lösung (mittelst Chlornatrium) direct durch oxalsaures Ammon nachzuweisen, es entstand hierdurch eine deutliche Trübung und später ein Bodensatz von oxalsaurem Kalk.

Wasser- und Aschegehalt entsprachen den bisher dafür erhaltenen Mengen.

$1,0075 \mathrm{Grm}$. Subst. verloren bei $110^{0} 0,1075 \mathrm{Grm} . \mathrm{H}_{2} \mathrm{O}=10,6{ }^{0}{ }_{0}$; die erhaltenen 0,9000 Grm. Trockensubst. gaben 0,0035 Grm. Asche $(=0,39 \%)$, welche nach Glühen vor dem Gebläse auf $0,0020 \mathrm{Grm} .=$ $0,22 \%$ sich verminderte.

In der infolge Eisengehaltes schwach gelblich gefärbten Asche bestimmte ich den Kalk durch oxalsaures Ammon und erhielt nach Glühen vor dem Gebläse 0,0006 Grm. CaO $=0,07 \%$ an Phosphorsäure fand ich in obiger Asche 0,00028 Grm. $\mathrm{P}_{2} \mathrm{O}_{5}=14,0 \%$ der Asche.

Zur Anstellung weiterer Versuche mit diesem Eiweisse stand mir genügendes Material nicht zu Gebote.

Eine Zusammenstellung der Ergebnisse, welche die angestellten Untersuchungen über das krystallinische Eiweiss bisher geliefert haben, zeigt im Wesentlichen eine Ueber- 
einstimmung der Eigenschaften aller der beschriebenen Eiweisskrystalle. Dieselben lassen weder in der Form, die durchgängig octaëdrisch ist, noch im Verhalten gegen Lösungs- und Fällungsmittel, noch beim Vergleiche der Elementaranalysen Verschiedenheiten entdecken. Demzufolge könnte man mit einigem Rechte annehmen, dass in allen Fällen dasselbe krystallinische Eiweiss, unabhängig von dem als Lösungsmittel verwendeten Salze, auskrystallisirt, und das Salz selbst an der Bildung der Eiweisskrystalle chemisch nicht betheiligt sei. Dieser Annahme entgegen stehen aber die Resultate, welche sich bei Prüfung auf anorganische Bestandtheile der Eiweisskrystalle ergaben. Danach war in dem untersuchten Eiweisse, theils direct in der Lösung, theils nach Veraschung, stets noch das zur Darstellung verwendete, anorganische Salz, wenn auch in geringer Menge, nachzuweisen. In den Fällen, wo sowohl Base als Säure des betreffenden anorganischen Salzes quantitativ bestimmt wurde, ergab sich ein Zahlenverhältniss der Säure zur Base, welches annähernd der Zusammensetzung des zur Darstellung angewendeten Salzes entsprach. Daraus lässt sich im Gegensatze zur ersteren Annahme folgern, dass dem bei der Eiweisskrystallisation angewendeten Salze eine chemische Betheiligung zugeschrieben werden kann, derart, dass. das Salz als solches mit dem Eiweisse eine Verbindung bildet. Beweisend für letztere Ansicht scheint mir auch noch der Umstand zu sein, dass trotz aller Reinigungsversuche des Eiweisses der Gehalt an Aschebestandtheilen (z. B. der phosphorsauren Salze) bisher nicht unter das Minimum von 0,15 . bis $0,2 \% \mathrm{zu}$ bringen war.

\section{Verbindungen von Magnesia und Kalk mit Eiweiss.}

1. Magnesiaverbindung.

Eiweissniederschlag wurde in Wasser vertheilt und dieser Flüssigkeit unter Erwärmen auf $40^{\circ}$ allmählich kleine Mengen Magnesia zugesetzt, so lange, bis unter Eintreten einer deutlich alkalischen Reaction das Eiweiss in Lösung gegangen 


\section{Grübler: Ueber ein krystallinisches Eiweiss}

war. $\left.{ }^{1}\right)$ Nach genügender Digestion wurde warm abfiltrirt und die nach mehrmaligem Rückgiessen endlich klar erhaltcne Eiweisslösung langsam erkalten gelassen. Das dann ansgeschiedene Eiweiss bestand aus mikroskopisch kleinen, durchsichtigen Krystallkörnern, vermischt mit einzelnen, deutlich ausgebildeten Octaëdern. An Grösse erreichten die Krystalle die vorhergehenden kaum zur Hälfte, waren jedoch bezüglich der übrigen Eigenschaften in der Hauptsache den bisher beschriebenen Eiweisskrystallen gleich. Der Aschegehalt wurde jedoch beträchtlich höher gefunden:

$0,8408 \mathrm{Grm}$. Substanz $=0,7629 \mathrm{Grm}$. Trockensubst. gaben 0,0044 Grm. Asche $=0,58 \%$.

In der Asche wurde nach Entfernung einer Spur Eisen durch essigsaures Natron die Magnesia als phosphorsaure Ammon-Magnesia gefällt und nach Glühen als pyrophosphorsaure Magnesia bestimmt. Ich erhielt:

$0,0098 \mathrm{Grm} .2 \mathrm{MgO} \mathrm{PO}_{\overline{5}}=0,0085 \mathrm{Grm} . \mathrm{MgO}=0,046 \%$ für Trockensubstanz.

Die von diesen Eiweisskrystallen restirende Mutterlauge wurde bei $40^{\prime \prime}$ zur Trockne verdampft und lieferte eine geringe Menge einer glasigen, spröden Masse, welche, zu feinem Pulver zerrieben, ebenfalls auf den Gehalt an Magnesia geprüft wurde.

1,0700 Grm. Subst. verloren bei $110^{\circ} 0,790$ Grm. Wasser $=7,8^{0}{ }_{0}$; die erhaltenen 0,9310 Grm. Trockensubst. gaben 0,0462 Grm. Asche $=4,9 \%$. Dic Asche lieferte 0,0507 Grm. $2 \mathrm{MgOPO}_{5}=0,0183 \mathrm{Grm}$. $\mathrm{MgO}=1,96$ Grm. $\mathrm{MgO}$ für Trockensubst.

Der unlösliche Rückstand endlich, welcher bei Digestion des Eiweisses mit Magnesia verblieb, lieferte 4,2\% Asche, die neben Phosphorsäure und Eisenoxyd hauptsächlich Magnesia enthielt.

Bei einer wiederholten Darstellung der Magnesiaverbindung nahm ich zugleich auf die Löslichkeitsverhältnisse Rücksicht.

Der Eiweissniederschlag wurde in $400 \mathrm{Ccm}$. Wasser

1) Eine vollständig klare Lösung komte ich jedoch nie erzielen, sonderu as bildete sich.stets ein geringer amorpher Bodensatz. 
vertheilt, mit Magnesia digerirt und aus der Lösung auf die beschriebene Weise Krystalle erhalten. Die über den Krystallen befindliche Lauge enthielt auch nach längerem Stehen noch viel kleine Eiweisskrystalle suspendirt, und konnte nur durch Centrifugiren davon befreit und als völlig klare Flüssigkeit erhalten werden. Das durch Krystallisation ausgeschiedene Eiweiss ergab nach dem Trocknen ein Gesammtgewicht von 5,5 Grm.

Die Mutterlauge der Krystalle lieferte nach Verdampfen einen glasigen Rückstand im Gewichte von 2,7 Grm.

Das erhaltene krystallinische Eiweiss sowohl, als den trocknen Verdampfungsrückstand der Mutterlauge prüfte ich ebenfalls auf Gehalt an Asche und Magnesia.

Krystallinisches Eiweiss:

1,0525 Grm. Substanz $=0,9645$ Grm. Trockensulbst. gaben 0,0050 Grm. Asche $=0, \tilde{5} 2 \%$.

Die Asche ergab 0,0166 Grm. $2 \mathrm{MgOPO}_{5}=0,0044$ Grm. $\mathrm{MgO}=$ $0,45 \% \mathrm{MgO}$.

Rückstand der Mutterlauge:

1,4525 Grm. Substanz $=1,2915$ Grm. Trockensubst. gaben 0,0605 Grm, Asche $=5,3 \% 0^{\circ}{ }^{1}$ )

Die Asche gab $0,0650 \mathrm{Grm}$. $2 \mathrm{MgOPO}_{5}=0,0234$ Grm. $\mathrm{MgO}=$ $1,81 \%$ für Trockensubst.

Die 2,7 Grm. Eiweiss des Rückstandes enthiclten also 0,0435 Grm. $\mathrm{MgO}$, danach waren in $400 \mathrm{Ccm}$. Flüssigkeit bei $40^{\circ}$ annähernd 8,0 Grm. Eiweiss und 0,0734 Grm. MgO gelöst, $=2 \%$ Eiweiss und $0,00188^{\circ} ; \mathrm{MgO}$.

Für erwähnenswerth halte ich noch das Resultat der Aschenanalysen des krystallinischen Eiweisses und des amorphen Rückstandes der Mutterlauge. Beide Aschen gaben in salzsaurer Lösung durch Kochen mit essigsaurem Natron Eisenniederschläge, doch enthielt der Eisenniederschlag der

1) Das gefundene Mehrgewicht dieser Asche (wie dasjenige der ersten Darstellung) im Vorgleich zum Magnesiagehalte rührte nur zum Theil von Alkalisalzen und Eisen her; zumeist muss es der vorhandenen Phosphorsäure zugeschrieben werden. Vermuthlich war auch schon ein Theil der Magnesia in der Eiweisslösung als phosphorsaures Salz gelost. 


\section{Grübler: Ueber ein krystallinisches Eiweiss}

ersteren Asche vorwiegend reines Eisenoxyd, neben Spureu von Phosphorsäure, während in der zweiten Asche sowohl der Eisenniederschlag, als die davon restirende Lösung reichlich Phosphorsäure enthielt. Dies lässt darauf schliessen, dass die Magnesia während der Digestion dem Eiweisse den grössten Theil der Phosphorsäure entzieht, indem sie damit theils den unlöslichen Digestionsrückstand bildet, theils, wie bereits in der Anmerkung erwähnt wurde, als phosphorsaures Salz in Lösung geht.

Die Elementaranalysen dieser krystallinischen Eiweissverbindung gaben für Trockensubstanz etwas niedrigere Zahlen, als die vorhergehenden; es ist dies zum Theil wohl auf den höheren Aschegehalt zurückzuführen, zum Theil vielleicht auch auf die geringere Reinheit der Substanz, da letztere wegen ihrer sehr kleinen Krystalle nicht genügend auszuwaschen war. Ich habe deshalb die Werthe für aschefreie Substanz beigefügt.

\section{Elementaranalyse.}

Wasser- und Aschebestimmung:

1,0525 Grm. Substanz verloren bei $110^{\circ} 0,0880$ Grın. Wasser $=$ $8,36 \%$; die erhaltenen 0,9645 Grm. Truckensubst. gaben $0,0050 \mathrm{Grm}$. Asche $=0,52 \%$.

Kohlenstoff- und Wasserstoffbestimmung:

0,2625 Grm. Subst $=0,2406$ Grm. Trockensubst. $=0,2392$ Grm. aschefreie Subst. gaben:

0,1602 Grm. $\mathrm{H}_{3} \mathrm{O}=0,0178 \mathrm{Grm} . \mathrm{H}\left\{\begin{array}{l}=7,20 \% \text { f. Trockensubst. } \\ =7,24 \% \text { f. aschefr. Subst. }\end{array}\right.$

$$
0,4645 \quad " \quad \mathrm{CO}_{2}=0,1267 \quad \text { C }\left\{\begin{array}{l}
=52,60 \% \text { f. Trockensubst. } \\
=52,95,, \text { f, aschefr. Subst. }
\end{array}\right.
$$

0,3510 Grm. Subst. $=0,3217$ Grm. Trockensubst. $=0,3199$ Grm. aschefreie Subst. gaben:

$$
\begin{aligned}
& 0,2088 \text { Grm. } \mathrm{H}_{2} \mathrm{O}=0,0232 \text { Grm. } \mathrm{H}\left\{\begin{array}{l}
=7,21 \% \text { f. Trockensubst. } \\
=7,25 \% \text { f. aschefr. Subst. }
\end{array}\right. \\
& 0,6220-\quad " \mathrm{CO}_{2}=0,16963 \quad \text { \# } \mathrm{C}\left\{\begin{array}{l}
=52,73 \% \text { f. Trockensubst. } \\
=53,02 \% \text { f. aschefr. Subst. }
\end{array}\right.
\end{aligned}
$$

Stickstoffbestimmung:

0,2340 Grm. Subst. $=0,2194$ Grm. Trockensubst. $=0,2133$ Grm. aschefreie Subst. gaben $36,0 \mathrm{Ccm}$. $\mathrm{N}$ bei $15,5^{\circ}$ und $751,5 \mathrm{Mm}$. Bar. 
$=0,041579$ Grm. $\mathbf{N}\left\{\begin{array}{l}=18,95 \% \text { \%. Trockensubst. } \\ =19,02 \% \text { f. aschefr. Subst. }\end{array}\right.$

0,2165 Grm. Subst. $=0,1985$ Gru. Trockensubst. $=0,1973 \mathrm{Grm}$ aschefi. Subst. gaben $33,5 \mathrm{Ccm}$. N bei $16,0^{\circ}$ und $739,0 \mathrm{Mm}$. Bar.

$$
=0,03751 \text { Grm. H }\left\{\begin{array}{l}
=18,89 \% \text { f. Trockensubst. } \\
=18,96 \% \text { f. aschefr. Subst. }
\end{array}\right.
$$

Schwefelbestimmung:

$0,8220 \mathrm{Grm}$. Subst. $=0,7535$ Grm. Trockensubst. $=0,7496$ Grm. aschefr. Subst. gaben 0,0521 Grm. $\mathrm{BaSO}_{4}=0,00724 \mathrm{Grm}$. S

$$
=0,00724 \text { Grm. } S\left\{\begin{array}{l}
=0,96 \% \text { f. Trockensubst. } \\
=0,97 \% \text { f. aschefr. Subst. }
\end{array}\right.
$$

\begin{tabular}{|c|c|c|c|c|c|c|c|}
\hline \multicolumn{4}{|c|}{ Trockensubstanz. } & \multicolumn{4}{|c|}{ Aschefreie Substanz. } \\
\hline & $\begin{array}{c}\text { Analyse } \\
\mathrm{I} .\end{array}$ & $\begin{array}{c}\text { Analyse } \\
\text { II }\end{array}$ & Mittel. & & $\begin{array}{l}\text { Analyse } \\
\text { I. }\end{array}$ & $\begin{array}{c}\text { Analyse } \\
\text { II. }\end{array}$ & Mittel. \\
\hline $\mathrm{C}$ & 52,60 & 52,73 & 52,66 & C & 52,95 & 58,02 & 52,98 \\
\hline $\mathrm{H}$ & 7,20 & 7,21 & 7,20 & $\mathrm{H}$ & 7,24 & 7,25 & 7,25 \\
\hline $\mathbf{N}$ & 18,95 & 18,89 & 18,92 & $\mathrm{~N}$ & 19,02 & 18,96 & 18,99 \\
\hline $\mathbf{S}$ & 0,96 & - & 0,96 & $\mathbf{S}$ & 0,97 & - & 0,97 \\
\hline 0 & - & - & 19,74 & 0 & - & - & 19,81 \\
\hline \multirow[t]{2}{*}{ Asche } & 0,52 & 0,52 & 0,52 & & & & \\
\hline & & & 100,00 & & & & 100,00 \\
\hline
\end{tabular}

Procentische Werthe.

2. Kalkverbindung.

Die Anwendung des kaustischen Kalks zur Darstellung von krystallinischem Eiweiss erfordert mehr Vorsicht, da Kalkhydrat sehr energisch auf frisch gefälltes Eiweiss einwirkt. Letzteres liess sich schon bei Anwendung von Kalkwasser beobachten, welches trotz seines geringen Kalkgehaltes den darin vertheilten Eiweissniederschlag schnell in grosse käsige Flocken verwandelte, die sich ähnlich dem geronnenen Eiweisse verhielten und später den Boden des Gefässes als unlösliche, schwammige Masse bedeckten; Chlornatrium und verdünntes Alkali vermochten es dann nicht mehr zu lösen. Verdünntes Kalkwasser von noch deutlich alkalischer Reaction verlor dieselbe beim Vermischen mit einer hinreichenden Menge von Eiweissniederschlag; die dann. 


\section{Grübler: Ueber ein krystallinisches Eiweiss}

neutral reagirende Flüssigkeit enthielt jedoch nur wenig Eiweiss gelöst.

Behufs Darstellung der Krystalle vertheilte ich Eiweissniederschlag in viel Wasser und setzte unter Umschütteln tropfenweise Kalkwasser so lange zu, bis sich eine schwach alkalische Reaction bemerkbar machte. Hierauf digerirte ich unter weiterem vorsichtigen Zusetzen von Kalkwasser bei $40^{\circ}$, bis die Flüssigkeit unter Abscheidung eines geringen gelblichen Bodensatzes durchscheinend geworden war. Die so dargestellte Lösung wurde nach Filtration in der Wärme völlig wasserhell und schied nach dem Erkalten Eiweiss krystallinisch aus. Die erhaltenen Krystalle stimmten im Aussehen völlig mit denen der Magnesiaverbindung überein, verhielten sich auch bezüglich der übrigen Eigenschaften analog. Die Mutterlauge dieser Krystalle wurde nach dem Centrifugiren ebenfalls verdampft, bis zum Entstehen eines trocknen, glasigen Rückstandes.

Ich untersuchte auch hier das Eiweiss der Krystalle und des Rückstandes der Mutterlauge, sowie den während der Digestion entstandenen, unlöslichen Bodensatz.

A. Krystallinisches Eiweiss:

1,0390 Grm. Substanz verloren bei $110^{\circ} 0,1105$ Grm. Wasser $=$ $10,63 \%$; die erhaltenen 0,9285 Grm. Trockensubst. hinterliessen nach Glühen vor dem Gebläse 0,0115 Grm. Asche $=1,2 \%$.

Die salzsaure Lösung der Asche gab mit essigsaurem Natron einen rothbraunen Eisenniederschlag, der eine Spur Phosphorsäure enthielt; im Filtrat hiervon wurde der Kalk durch oxalsaures Ammon gefällt und als kaustischer Kalk bestimmt. Ich erhielt 0,0101 Grm. $\mathrm{CaO}=1,09 \%$ für Trockensubst.

B. Verdampfungsrückstand der Mutterlauge:

1,9510 Grm. Substanz $=1,7715$ Grm. Trockensubst. gaben 0,0608 Grm. Asche $=3,1 \%$, die sich nach Glühen vor dem Gebläse auf $0,0450 \mathrm{Grm} .=2,3 \%$ verminderte.

Der wässrige Auszug dieser Asche reagirte stark alkalisch; aus der salzsauren Lösung wurde durch essigsaures Natron wenig eines weissen, phosphorsäurehaltigen Eisenniederschlages gefallt. Der Kalkgehalt der Asche wurde wie bei der vorigen bestimmt und erhalten: 0,0194 Grm. CaO $=1,09 \%$ f. Trockensubst. 


\section{Der amorphe Digestionsrückstand}

ergab nach Veraschen 2,8\% Asche von rothbrauner Farbe und enthielt neben Eisenoxyd und Kalk viel Phosphorsäure.

Der Gehalt der zwei letzten krystallinischen Eiweisskörper an den zur Darstellung verwendeten Basen lässt wohl kaum noch in Zweifel darüber, dass hier wirkliche Verbindungen des Eiweisses mit alkalischen Erden bestehen, indem hierbei das Eiweiss die Stelle einer Säure vertritt. Berechnet man das Moleculargewicht dieses Eiweisses, so ergiebt sich, dass 40 Theile $\mathrm{MgO}$ mit $8848 \mathrm{Thln}$. Eiweiss, und $\mathbf{5 6}$ Thle. CaO mit 5081 Thln. Eiweiss verbunden sind. Diese Zahlen stehen ziemlich genau in dem Verhältnisse von $4: 7$, denn es sind dann

$$
\begin{array}{ccccc}
35,392 & \text { Thle. Eiweiss mit } 160 \text { Thln. } \mathrm{MgO} \text {, } \\
35,567 " 392 ~ " ~ & \text { CaO }
\end{array}
$$

verbunden; danach würden im Molekül des Eiweisses der Magnesiaverbindung $8 \mathrm{H}$-Atome durch $\mathrm{Mg}$, und im Eiweisse der Kalkverbindung 14 H-Atome durch $\mathrm{Ca}$ vertreten sein. Dieses Verhältniss muss etwas eigenthümlich erscheinen, findet aber seine Erklärung vielleicht in Folgendem:

Nach den Resultaten der Analysen betrug der Gehalt des krystallinischen Magnesiaeiweisses an Magnesia $0,45 \%$, der des amorph aus der Mutterlauge erhaltenen 1,82\%, während das auf analoge Weise aus der Kalkverbindung gewonnene Eiweiss in beiden Fällen 1,09\% $\mathrm{CaO}$ enthielt, also die bei der Darstellung gebildete, in Lösung befindliche Eiweissverbindung unverändert wieder ausgeschieden worden war.

Die ursprünglich in Lösung befindliche Eiweissverbindung der Magnesia besass vermuthlich eine der Kalkverbindung entsprechende Zusammensetzung, erlitt jedoch dann beim Auskrystallisiren eine Spaltung in der Weise, dass ein magnesiaarmes Eiweiss krystallinisch sich ausschied, während ein Eiweiss mit hohem Magnesiagehalte in der Mutterlauge gelöst blieb. 
Verhalten des Eiweisses gegen Salze schwerer Metalle.

Die Untersuchungen erstreckten sich hier nur auf amorphe Eiweissverbindungen, da es mir, wie bereits angedentet, nicht gelang, unter Anwendung dieser Salze Eiweisskrystalle darzustellen.

Eingehendere Versuche über das Verhalten des Kupfers zum Eiweiss verdanken wir bereits Ritthausen ${ }^{1}$ ), welcher bei seinen Untersuchungen Kupforsalzlösungen vielfach als Fällungs- und Trennungsmittel von pflanzlichen Eiweisskörpern anwendet und die Zusammensetzung des Eiweisses ans den Analysen der erhaltenen Kupferverbindungen ableitet. Seine spätere Mittheilung über Ricinussameneiweiss vervollständigte diese Untersuchungen noch weiter durch Analysen der erhaltenen Kupferverbindungen.

Das Verfahren, dessen ich mich zur Darstellung der Kupferverbindung des Einweisses bediente, unterschied sich im Wesentlichen nicht von der Methode Ritthausen's. Eine Lösung des Eiweisses in Chlornatrium wurde mit Kupfersalzlösung im geringen Ueberschusse versetzt und der erhaltene, bläulich-weisse Niederschlag mit Wasser ausgewaschen, so lange die zuletzt eintretende starke Quellung es noch gestattete. Nach Zusatz von Alkohol schrumpite der Niederschlag zusammen, so dass er durch Pressen zwischen Fliesspapier und Stehen an der Luft trocken erhalten werden konnte; derselbe stellte dann eine hornartige grüne Masse dar, die sich leicht zu bläulich-weissem Pulver zerreiben liess. Wurde der Niedersehlag unter Anwendung von Alkohol und Aether getrocknet, so lieferte er ein lockeres Pulver von der bläulich-weissen Farbe des frischen Niederschlages. Letzteres prüfte ich auf Wasser- und Aschegehalt:

0,8365 Grm. Substanz verloren bei $110^{\circ} 0,0930 \mathrm{Grm}$. Wasser $=$ 11,1 \%; die erhaltenen 0,7433 Grm. Trockensubst. gaben 0,0138 Grm. Asche $=1,8 \%$

Die Asche besass eine schwarz-grüne Farbe und war

1) In seinem Werke: Die Eiweisskörper cte. 
stark phosphorsäurehaltig; aus der salzsauren Lösung der. selben wurde das Kupfer mittelst Zink ausgeschieden und als Metall bestimmt.

0,7433 Grm. Trockensubstanz gaben 0,0061 Grm. $\mathbf{C u}=0,82 \%=$ 0,0076 Grm. $\mathrm{CuO}=1,08 \%$.

Der Phosphorsäuregehalt dieser Substanz betrug 1,55\%, und lässt dies, namentlich im Vergleich mit dem niederen Kupfergehalte des krystallinischen Eiweisses, annehmen, dass der in amorphen Kupferverbindungen gefundene Kupfergehalt infolge Beimengung von phosphorsaurem Kupfer ein zu hoher ist.

Bezüglich der Eigenschaften des Kupfereiweissniederschlages bestätigten sich die von Ritthausen mitgetheilten Beobachtungen; er löste sich, frisch und getrocknet, in verdünnter Kalilauge, leichter noch in ammoniakhaltigem Wasser mit schön violetter Farbe auf und schied sich beim Neutralisiren wieder aus; ein Versuch, aus der ammonhaltigen Lösung durch Alkoholdialyse Krystalle zu erhalten, hatte keinen Erfolg. Bei längerem Stehen ging die violette Farbe der Lösung allmählich in Braun über, vermuthlich infolge Bildung von Schwefelkupfer, ohne jedoch dabei den für Eiweissfäulniss charakteristischen Geruch auftreten zu lassen.

Weniger bekannt scheint die Eigenschaft von Kupfersalzen und einiger anderer Metallsalze zu sein, lösend auf frisch gefälltes Eiweiss zu wirken. Den im Wasser vertheilten Eiweissniederschlag vermochte ich durch Zusatz von Kupferlösung zu einer völlig klaren, bläulichen Flüssigkeit zu lösen; beim Erwärmen nahm die Lösung, analog den Alkalisalzen, noch mehr Eiweiss auf, welches nach dem Erkalten amorph wieder ausgeschieden wurde. Auf Zusatz von wenig Chlornatrium zur Kupfereiweisslösung trat sofort flockige Ausscheidung des Eiweisses ein, und zeigte sich sonach hier die eigenthümliche Erscheinung, dass dieselbe Salzlösung sowohl als starkes Lösungs-, als als starkes Fällungsmittel des Eiweisses auftreten kann.

Versuche über das Verhalten von Salzen anderer schwerer Metalle (wie Zinnchlorür und -chlorid, neutrales und basischessigsaures Blei) ergaben genau dieselben Resultate, doch 


\section{Grübler: Ueber ein krystallinisches Eiweiss}

scheinen Bleisalze noch energischer lösend auf das Eiweiss zu wirken, da eine so dargestellte Lösung auch nach Zusatz grosser Mengen Wassers nicht wieder gefällt wurde.

Eine Zusammenstellung der Resultate, welche aus diesen Untersuchungen hervorgehen, ergiebt Folgendes:

1) Die Kürbissamen enthalten ein Eiweiss, welches leicht in gut ausgebildeten Krystallen erhalten werden kann; dasselbe krystallisirt in regulären Octaëdern.

2) Die in den Kürbissamen enthaltene Proteinsubstanz besteht zum weitaus grössten Theile aus dem octaëdrisch krystallisirenden Eiweisse; letzteres bildet vielleicht den alleinigen Eiweisskörper der Proteinsubstanz, da noch nicht erwiesen ist, dass das nach Fällung und Krystallisation in den Laugen in geringer Menge gefundene Eiweiss ein anderes ist.

3) Das eingeschlagene Verfahren der Darstellung des krystallinischen Eiweisses (nach Drechsel) unter Anwendung von Salzen ist vor allen anderen jetzt bekannten Methoden dazu geeignet, einen reinen, unveränderten Eiweisskörper in Krystallen zu gewinnen.

4) Die künstlichen Eiweisskrystalle sind in der Krystallform übereinstimmend mit den natürlichen Proteïnkrystallen; eine wesentliche Zersetzung des genuinen Eiweisses infolge der Behandlungsweise zur Darstellung der künstlichen Krystalle ist demnach nicht anzunehmen.

5) Auch nach dem Verfahren von Ritthausen kann ein Eiweiss gewonnen werden, welches, gleich dem Weyl'schen Vitellin, octaëdrische Krystalle liefert, worans hervorgeht, dass dasselbe durch die angewandte Methode keine Veränderung erlitten hat.

6) Frisch gefälltes Eiweiss wird schon durch Einfluss freier Kohlensäure verändert.

7) Die Coagulationstemperatur des Eiweisses ist abhängig von dem Salzgehalte der Lösung und steigt entsprechend der Menge des zum Lösen des Eiweisses verwendeten Salzes. 
8) Obgleich die aus verschiedenen Salzlösungen erhaltenen krystallinischen Eiweisse sämmtlich dieselbe Krystallform besitzen, ist es doch möglich, dass sie mit geringen Mengen der betreffenden anorganischen Salze Verbindungen bilden, da in dem darauf untersuchten Eiweisse stets das zur Krystallisation verwendete Salz deutlich nachzuweisen war.

9) Beim öfteren Umkrystallisiren des Eiweisses verschwindet der Phosphorsäuregehalt schliesslich fast vollständig; die Phosphorsäure ist demnach nicht ein integrirender Bestandtheil des Eiweisses, wie etwa des Lecithins oder Nucleïns, sondern vielleicht als Salz mit ihm verbunden, wie Kochsalz, schwefelsaure Magnesia, Chlorammonium u. s. w. in den beschriebenen Krystallen.

10) Die krystallinischen Verbindungen des Eiweisses mit alkalischen Erden besitzen ebenfalls octaëdrische Krystallform; sie zeichnen sich gegenüber den Eiweisskrystallen der Salzlösungen durch einen höheren Gehalt an der zur Darstellung benutzten Basis aus, und vertritt hier das Eiweiss die Stelle einer Säure.

11) Das Moleculargewicht dieses Eiweisses berechnet sich aus den Verbindungen der alkalischen Erden für Magnesiaeiweiss auf 8848, für Kalkeiweiss auf 5081, und lässt sich die Verschiedenheit dieser Moleculargewichte vielleicht auf die leichte Veränderlichkeit der Magnesiaverbindung gegenüber der Kalkverbindung zurückführen.

12) Das krystallinische Eiweiss unterscheidet sich von dem amorphen:

1) durch einen weit geringeren Asche- und Phosphorsäuregehalt;

2) durch einen höheren Gehalt an Kohlenstoff, Stickstoff und Schwefel.

Ein Vergleich der Analysen von aus Chlornatriumlösung amorph (A) und krystallinisch (B) erhaltenem Eiweisse giebt folgende procentische Werthe. 
136 Grübler: Krystallinisch. Eiweiss d. Kürbissamen.

$$
\begin{gathered}
\text { A. Amorphes Eiweiss } \\
\text { (nach Barbieri). } \\
\mathrm{C}=51,88 \% \\
\mathrm{H}=7,51 \% \\
\mathrm{~N}=18,08 \% \\
\mathrm{~S}=0,60 \% \\
\mathrm{O}=\frac{21,93 \%}{100,00} \\
\text { Asche }=1,11 \%
\end{gathered}
$$

B.

Krystallinisches Eiweiss.

$$
\begin{aligned}
\mathbf{C} & =53,21^{\circ}{ }_{0} \\
\mathbf{H} & =7,22 " \\
\mathbf{N} & =19,22 " \\
\mathrm{~S} & =1,07 " \\
\mathrm{O} & =19,10 " \\
\text { Asche } & =\frac{0,18 "}{100,00}
\end{aligned}
$$

Danach enthält das krystallinische Eiweiss doppelt so viel Schwefel, als das amorphe, und einen Mehrgehalt an Kohlenstoff von $1,5 \%$, und Stickstoff von $1,0 \%$. Dagegen enthält das amorphe Eiweiss ein Plus von $0,47 \% \mathrm{H}$, welches einer Gewichtsmenge von 4,30\% $\mathrm{H}_{2} \mathrm{O}$ entsprechen würde.

Vergleicht man die procentische Zusammensetzung des krystallinischen Eiweisses mit dem amorphen in der Weise, dass die procentischen Werthe der einzelnen Bestandtheile, des krystallinischen auf C 51,88. berechnet werden, so ergiebt sich in nachstehenden Zahlen ein Minus von 2,52\%

$$
\begin{array}{lrr}
\mathbf{C} & = & 51,88 \\
\mathrm{H} & = & 7,04 \\
\mathrm{~N} & = & 18,74 \\
\mathrm{~S} & = & 1,04 \\
\mathrm{O} & = & 18,62 \\
\text { Asche } & =0,16 \\
\cline { 2 - 3 } & & 97,48
\end{array}
$$

Nehmen wir dieses Minus als Wasser an und ziehen von den Zahlen der Barbieri'schen Analyse die entsprechende Menge Wasserstoff und Sauerstoff ab, so erhalten wir folgende Zahlen:

$$
\begin{aligned}
& \mathrm{C}=51,88 \\
& \mathrm{H}=7,23 \\
& \mathrm{~N}=18,08 \\
& \mathrm{~S}=\frac{0,60}{\mathrm{O}}=\frac{19,69}{97,48}
\end{aligned}
$$

welche mit den von mir für das krystallinische Eiweiss gefundenen hinreichend übereinstimmen, um die Annahme zu unterstützen, dass beide Eiweisspräparate sich in ihrer $Z_{\mathbf{n}}$ - 
r. Perger: Bildung von Dihydroanthranol etc. 137 sammensetzung nur durch einen verschiedenen Wassergehait unterscheiden. Barbieri's amorphes Eiweiss müsste demnach eine gewisse Menge Wasser enthalten, welches bei $110^{\circ}$ noch nicht entweicht.

Leipzig. Physiolog. Institut, im August 1880.

\section{Ueber die Bildung von Dihydroanthranol und Anthracen aus Anthrachinon;}

von

\section{Dr. Hugo R. von Perger.}

C. Graebe und C. Liebermann haben schon vor zehn Jahren die Reductionsfähigkeit des Anthrachinons durch Zinkstaub und Kalilauge beschrieben und den durch diese Reaction entstehenden, in Alkalien mit blutrother Farbe löslichen, leicht wieder in Anthrachinon umwandelbaren Körper Anthrahydrochinon genannt. ${ }^{1}$ ) Ueber die Eigenschaften und Zusammensetzung dieser Verbindung hat C. Liebermann erst vor kurzer Zeit höchst interessante Mittheilungen gemacht und die Constitution des "Oxanthranols" durch die Formel

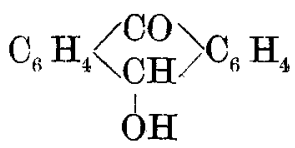

zum Ausdruck gebracht. ${ }^{2}$ ) Von C. Liebermann und Topf ${ }^{3}$ ) wurde durch Einwirkung von Jodwasserstoffsäure und Phos-

1) Ber. Berl. chem. Ges. 1870, S. 636.

2) Das. 1880, S. 1596.

3) Das. 1876, S. 1201. 